\title{
Perception des végétaux chez les Ribeirinhos d'Amazonie brésilienne
}

Approche ethnobotanique dans la forêt nationale du Tapajós

Plants perception of the Ribeirinhos in the Brazilian Amazon : ethnobotanical approach in the Tapajós national forest

\section{Claire Couly}

\section{OpenEdition}

\section{Journals}

Édition électronique

URL : http://journals.openedition.org/ethnoecologie/1420

DOI : $10.4000 /$ ethnoecologie. 1420

ISSN : 2267-2419

\section{Éditeur}

Laboratoire Eco-anthropologie et Ethnobiologie

\section{Référence électronique}

Claire Couly, « Perception des végétaux chez les Ribeirinhos d'Amazonie brésilienne », Revue d'ethnoécologie [En ligne], 3 | 2013, mis en ligne le 19 novembre 2013, consulté le 30 avril 2019. URL : http://journals.openedition.org/ethnoecologie/1420; DOI : 10.4000/ethnoecologie.1420

Ce document a été généré automatiquement le 30 avril 2019

Revue d'ethnoécologie est mis à disposition selon les termes de la licence Creative Commons Attribution - Pas d'Utilisation Commerciale - Pas de Modification 4.0 International. 


\title{
Perception des végétaux chez les Ribeirinhos d'Amazonie brésilienne
}

\author{
Approche ethnobotanique dans la forêt nationale du Tapajós \\ Plants perception of the Ribeirinhos in the Brazilian Amazon : ethnobotanical \\ approach in the Tapajós national forest
}

\section{Claire Couly}

1 Cet article a pour objectif d'analyser la perception des végétaux d'une communauté de Ribeirinhos d'Amazonie brésilienne. Il traite successivement de l'identification et de la dénomination des plantes, de la correspondance entre nomenclature locale et nomenclature scientifique, et des catégories locales des végétaux cultivés et spontanés.

2 Cette étude a été menée dans la forêt nationale du Tapajós (FNT), une aire protégée brésilienne de 600000 ha couverte de forêt tropicale dense et située dans l'est de l'État du Pará, au sud de la ville de Santarém (Carte 1). La rive droite du fleuve Tapajós est peuplée essentiellement de Ribeirinhos venus s'installer dans la région il y a 150 ans environ au début de la période extrativiste, succédant à la présence des Amérindiens Tapajós et Mundurucus sur ce territoire (Couly 2009). Les Ribeirinhos, aussi appelés caboclos, sont issus du métissage entre Amérindiens et premiers colons européens arrivés en Amazonie ; ils vivent communément le long des fleuves en Amazonie. Ils pratiquent une agriculture familiale d'autosubsistance basée sur l'agriculture sur brûlis, avec comme plante principale le manioc (Photographie 1), complétée par des activités de chasse, de pêche et d'extractivisme forestier. Par ses différentes composantes, le système local de production est analogue à celui pratiqué par l'ensemble des populations riveraines d'Amazonie (Denevan \& Padoch 1988 ; Padoch \& De Jong 1992). 
Carte 1. Localisation de la forêt nationale du Tapajós (en vert sur la carte du Brésil) et de notre village d'étude (Acaratinga) au sein de l'aire protégée (cercle noir sur la carte de droite)

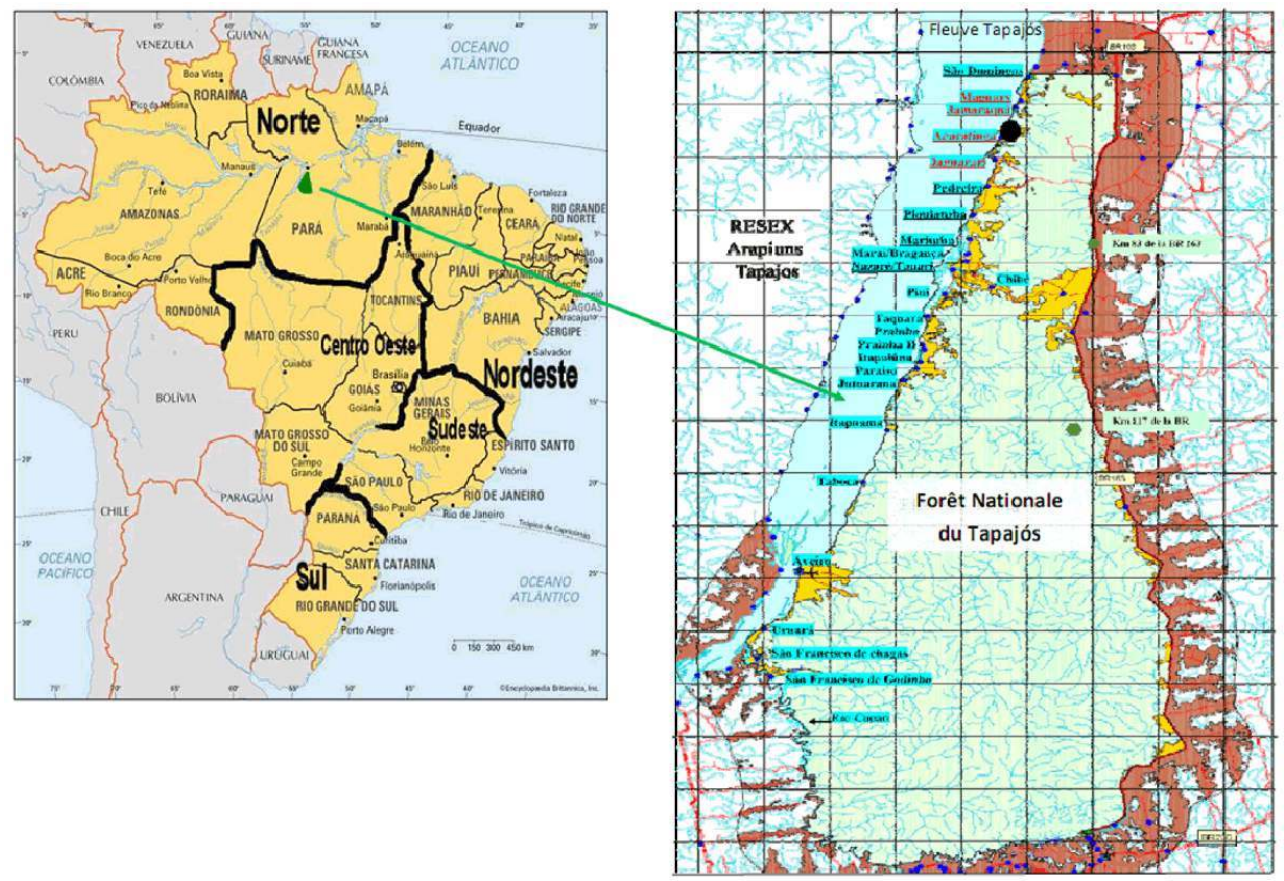

Photographie 1. Abattis dans la forêt nationale du Tapajós

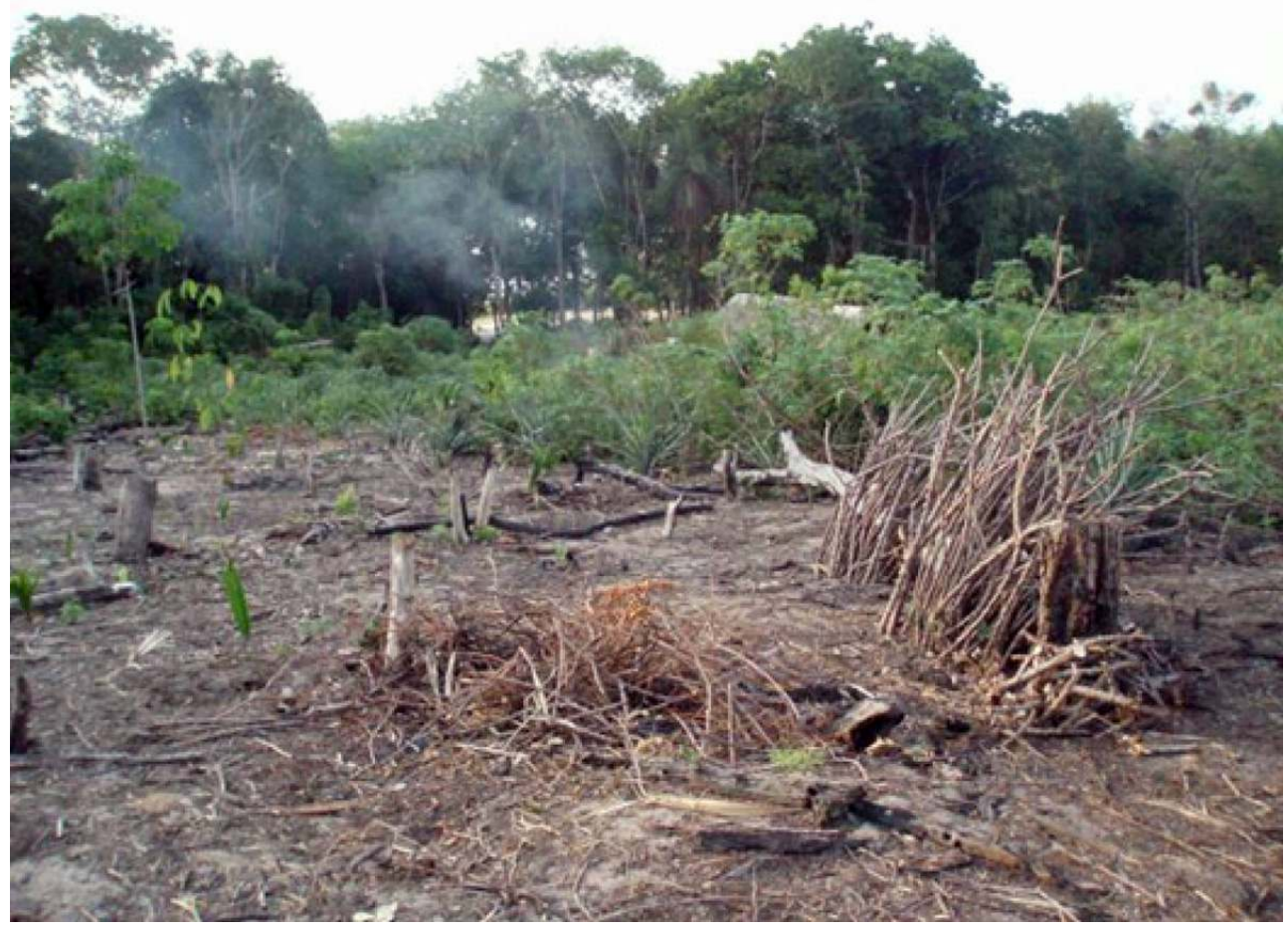

C. Couly

3 Deux missions de terrain ont été réalisées dans la FNT dans le cadre de mon doctorat (octobre à décembre 2006 et juin à septembre 2007), plus particulièrement dans le village d'Acaratinga, situé au nord de la FNT (Carte 1, coordonnées 5503"13 O / 251"07 S). Une 
autorisation du Conseil de gestion du patrimoine génétique (CGEN) a été obtenue au préalable pour mener cette recherche.

4 Une approche en ethnobiologie et en ethnobotanique quantitative a été developpée afin d'analyser les savoirs écologiques locaux et les mettre en parallèle avec les connaissances scientifiques. Ceci s'est traduit par: i) la réalisation d'inventaires ethnobotaniques et écologiques dans les jardins, abattis et forêts en compagnie d'informateurs locaux (dont un inventaire de tous les arbres, arbustes, lianes, palmiers de diamètres à hauteur de poitrine $\geq 5 \mathrm{~cm}$ sur 2,3 ha de parcelles forestières); ii) un suivi des prélèvements des ressources végétales et animales dans les familles villageoises, iii) le recueil et analyse des discours villageois relatifs aux plantes (retranscrits par la suite), iv) des observations participantes. La méthodologie est détaillée dans Couly (2009). Tous les échantillons botaniques récoltés ont été déposés et identifiés (Annexe) à l'herbier de l'Embrapa Amazônia Oriental (Belém, Brésil).

Nous nous intéressons dans le cadre de cet article aux végétaux cultivés (issus des abattis et jardins) et spontanés (forestiers ou adventices), indépendamment du critère d'utilité des plantes pour les Ribeirinhos (pour une analyse d'ethnobotanique quantitative focalisée sur les espèces forestières utiles se référer à Couly \& Sist (2012). L'analyse de la superposition de la taxonomie et parataxonomie s'est focalisée sur les espèces végétales forestières car celles-ci ont pu être identifiées par différents informateurs locaux lors d'inventaires ethnobotaniques menés dans des parcelles forestières.

$6 \quad$ Les discours ou expressions des villageois insérés dans le corps du texte sont indiqués en italique s'ils apparaissent en portugais et entre guillemets droits mais sans italique lorsqu'ils sont retranscrits directement en français. Des précisions ont pu être apportées directement dans les citations traduites afin de faciliter la compréhension des propos: elles sont alors indiquées soit entre parenthèses, lorsqu'il s'agit de la traduction littérale d'un mot ou d'une expression, soit entre crochets, lorsqu'il s'agit de précisions non formulées par l'interlocuteur. Les mots ou noms de plantes en portugais sont laissés en italique. Afin de rendre compte de la diversité des savoirs, nous avons indiqué à la fin de chaque citation le numéro de référence (entre crochets), attribué à chaque informateur local (15 hommes au total).

\section{Identification et dénomination}

7 La nomenclature des végétaux des Ribeirinhos se fonde sur des règles générales rencontrées dans les nomenclatures populaires. Les plantes sont désignées par un terme de base (ou nom de base) simple (ex: muirapixuna) ou composé (ex: pau de quina, littéralement " arbre quina »). Ce terme de base peut lui-même être suivi ou non d'un ou plusieurs déterminants: ex: louro preto ( "louro noir", terme de base simple + un déterminant), pimenta malagueta comum (" piment malagueta commun", terme de base simple + deux déterminants), pau de tocandeira amarelo (arbre tocandeira jaune, terme de base composé + un déterminant). Les plantes ayant le même terme de base sont regroupées dans une même série et sont distinguées par des déterminants différents (ex: dans la série du abiuzeiro: abiu vermelho ("abiu rouge »), abiu felpudo (" abiu à feuilles pubescentes »), abiu branco (" abiu blanc »), abiu cutite...). Cette terminologie reprend celle utilisée par Friedberg (1990). 
8 Les termes qualidade, marca, raça, tipo, ou espécie, sont couramment employés pour distinguer les plantes entre elles, qu'elles aient le même nom de base ou non. Selon le contexte de l'énonciation, ces termes locaux ne sont pas toujours synonymes, c'est-à-dire situés au même niveau taxonomique de la nomenclature populaire. Par exemple lorsqu'un informateur commente : " a ginja do quintal e a ginja da mata são da mesma raça, são duas qualidades » (« la ginja du jardin et la ginja de la forêt sont de la même race, ce sont deux qualités »), la "race» désigne ici le groupe du nom de base (ginja) et les « qualités » les déterminants. De façon générale, la qualidade est l'unité taxonomique minimale de reconnaissance d'un morphotype ${ }^{1}$. Pour reprendre l'exemple précédent, l'informateur qui distingue le ginja da mata (" ginja de la forêt») et le ginja do quintal (" ginja du jardin ») ne distingue pas d'autres sous-types de ces deux végétaux.

9 L'identification des plantes se fonde sur de nombreux critères faisant intervenir les caractéristiques morphologiques, olfactives et gustatives des différents organes et parties végétales (tronc, bois, feuilles, écorce, fruits, fleurs...).

“Je regarde d'abord l'écorce. Si je ne peux pas la reconnaître, j'en coupe un bout pour la sentir et pour regarder le bois, pour voir sa couleur ou voir s'il a des motifs (des dessins). Ensuite, je regarde la feuille..." [13]

Les critères morphologiques d'identification se reflètent le plus fréquemment dans les noms attribués aux végétaux, soit au niveau du terme de base (les termes de base composés seront suivis d'un astérisque* ci-dessous), soit, comme c'est le cas le plus fréquent, au niveau des déterminants. D’autres critères liés à la connaissance écologique des végétaux, à leur utilisation, ou encore à leur catégorisation, interviennent également dans la nomenclature locale. Celle-ci renseigne ainsi sur :

- les caractéristiques du bois (celui-ci est désigné localement par les termes madeira, carne, ou, pour le bois de coeur, cerne) :

- dureté : ex : louro pedra (« louro pierre », faisant allusion à la densité du bois), joão mole* (« joão tendre » car le bois est peu résistant)

- couleur : ex : angelim da branca («angelim blanc »)2, cumaru preto (« cumaru noir »), itaúba amarela/preta («itaúba jaune/noir »)

11 À noter que lorsqu'un arbre n'est pas reconnu par un identificateur, il est fréquemment désigné en fonction de la couleur du bois ou de sa dureté/ «fragilité » (madeira fraca/ madeira de lei), ces deux aspects étant en partie liés à l'abondance de l'aubier ou du duramen.

- les caractéristiques de l'écorce :

- couleur : ex : cipó preto* (« liane noire»), embaúba da branca/vermelha (embaúba «blanc/ rouge »), murteira da casca vermelha/branca (« murteira d'écorce rouge/blanche »)

- texture : ex : papelinho (" petit papier »), louro cascudo ("louro à écorce épaisse »), cipó liso* (« liane lisse »)

- relief : ex : pau de quina* (« arbre à tronc canelé »), cipó quina* (« liane quina »)

- goût : ex : fava amarga (« fava amère ») 
- odeur : ex : itaúba abacate (« itaúba avocat », l'odeur rappelant celle de l'avocat), cipó d'alho* (« liane ail»)

- les caractéristiques des fruits :

- couleur : ex : ipê amarelo/ipê roxo (« ipê jaune/rose »)

- taille : ex : ingá grande/pequeno (« ingá grand/petit»), cumaru grande/ cumaí (" grand cumaru /petit cumaru »)

- mode de déhiscence : ex : caracaxa (onomatopée faisant référence à l'éclatement de la gousse lors de la dissémination des graines)

- les caractéristiques des feuilles :

- pubescence : ex : abiu felpudo (« abiu pubescent »)

- taille: ex: louro da folha fina/louro da folha graúda («louro à petites feuilles/grandes feuilles »)

- la couleur des fleurs (ex : ipê branco/roxo («ipê blanc/rose ») ou des graines (tenteiro vermelho/ amarelo/flamengo , «tenteiro rouge/jaune/rouge et noir »)

- la présence d'exsudat ${ }^{3}$ dans le tronc (ex : breu sucuruba) ou la couleur de cet exsudat (ex : janitá vermelha (« janita rouge »), cipó de água* (« liane d'eau »).

- la taille des arbres ou des palmiers : ex : pitomba da grande/pitomba do pequeno («grand/petit pitomba »), tucumãí/ tucumã açú (" grand/petit tucumã »)

- la présence d'une écorce interne fibreuse (appelée localement envira) et sa caractéristique : ex : envira lisa/preta (« envira lisse/noire », sous entendu arbuste à envira lisse/noire)

- un détail morphologique caractéristique: ex: unha de gato* ("griffe de chat», dû à la présence de petites épines de la même forme sur cette liane), olho de veado* (« œil du daguet rouge », graine ayant une taille similaire à celle de l'œil de ce cervidé, le daguet rouge).

- l'utilisation faite du végétal : ex : pau de pilão* («arbre de pilon »), cipó de água*(« liane eau »), cipó xafari* ( liane xafarí », du nom de la technique (xafarí) utilisée pour extraire l'eau de la liane), caniceiro (« canne à pêche » [arbuste dont les branches servent à cet usage]), vassoura («balai »), facheiro («flambeau»), taxi de vara (arbre dont le bois sert à la fabrication de perche-vara- pour les pirogues), pau para tudo* («arbre pour tout » dont l'écorce est utilisée pour traiter toutes sortes de maux)

- le principal consommateur de la plante (qui est aussi l'agent disséminateur par exozoochorie ou endozoochorie) : ex : cipó macaco* («liane singe»), maracujá do rato (« maracujá du rat »), araçá do jaboti (" araçá de la tortue »), axuá do morcego (" axuá de chauvesouris »), erva de passarinho* (" herbe du petit oiseau »), castanha de arara* (" castanha du ara $)$

- le type d'insectes pouvant habiter le tronc: ex: pau de tocandeira* («arbre de la fourmi tocandeira »), taxi (« fourmi taxi »)

- le type de substrat ou d'écosystème de la plante : ex : itaúba da mata/do barro («itaúba de la forêt mature/de l'argile [de sol argileux] »), embaúba da mata/embaúba da capoeira (« embaúba de la forêt ancienne/de forêt secondaire »)

- une condition écologique particulière au développement de l'espèce : ex : seringa do amplo (« hévéa de clairière »)

- le caractère sauvage ou domestique de la plante : ex : ata da mata/ata planta (« ata de la forêt mature/ata planté »), araçá do quintal/araçá da mata (" araçá du jardin/de la forêt mature ») 
- l'origine de la plante (espèce locale ou exotique) : seringa nativa ("hévéa natif»), seringa americana (" hévéa américain », aussi appelée seringa do Oriente (« hévéa de l'est »).

Dans certains cas cependant, le principal critère d'identification n'apparaît pas dans le nom attribué au végétal. Le capitiú, par exemple, est connu par tous les informateurs interrogés comme ayant une odeur particulière de la feuille une fois celle-ci écrasée, ce caractère représentant le principal critère d'identification de cet arbuste. Cette caractéristique n'apparaît pourtant pas dans le nom final attribué à ce végétal et ce, pour aucun des villageois interrogés. À cela s'ajoute le fait que les informateurs distinguent deux types (qualidades) de capitiú (qui diffèrent par la taille de leurs feuilles et la couleur de l'écorce) auxquels ils n'attribuent pas de noms spécifiques, les deux étant simplement nommés par le terme de base. Les critères de reconnaissance et de distinction de ces deux plantes ne se reflètent donc pas dans le nom final attribué.

La dénomination d'une plante est parfois «opportuniste» et varie en fonction des critères mis en avant par l'informateur au moment où il est interrogé. Ainsi le louro itaúba est synonyme de louro da casca grossa ("louro à écorce épaisse ») et de louro da folha graúda ("louro à grandes feuilles ») pour un premier informateur. Un autre met en avant tantôt la pubescence des feuilles (abiu felpudo, «abiu à feuilles pubescentes ») tantôt la couleur de l'écorce (abiu vermelho, « abiu rouge ») pour désigner un même morphotype. À l'échelle de plusieurs informateurs, l'exemple de la vassoureira illustre bien cette variation dans les critères d'identification et de dénomination : en effet, certains distinguent (et nomment) les types de vassoureiras en fonction de leurs distributions (vassoureira da mata/capoeoira, " vassoureira de la forêt primaire/secondaire ») tandis que d'autres se réfèrent à la taille ( vassoureira baixa/alta, "vassoureira basse/haute») ou à la couleur de l'écorce (vermelha/ branca).

De plus, même s'ils nomment certaines plantes de façon similaire, il se pose par la suite le problème de leur correspondance. En effet, là où trois informateurs utilisent deux noms synonymes pour désigner un même morphotype (ex : "l'abiu rouge est de la même qualité que l'abiurana, c'est le même arbre"), pour quatre autres informateurs, ces deux mêmes noms concernent des morphotypes différents ("são qualidades diferentes" / «ce sont des qualités différentes»). Ceci s'applique également à des plantes de termes de base différents. Ainsi pour un des identificateurs, la murteira et la passarinheira sont des synonymes de la même plante tandis qu'un autre informateur distingue explicitement ces deux morphotypes.

La variation des critères de distinction se reflète également dans le nombre de qualidades distinguées par chaque informateur dans une même série ${ }^{4}$. Un informateur affirme par exemple qu'il n'existe que deux types d'itaúba (itaúba preta et itaúba vermelha), tandis qu'un autre informateur en distingue quatre en faisant une distinction supplémentaire en fonction du type de sol. De nombreux cas similaires ont ainsi été relevés auprès des différents informateurs.

Le rassemblement des morphotypes en familles est explicite et fait appel à des termes de parenté. De tels rapprochements se fondent sur des caractéristiques communes telles que l'appartenance à une même catégorie locale de végétaux (exemple 1), la présence de résine dans les arbres (exemple 2) ou la ressemblance des feuilles ou celles des fruits (exemple 3) :

"Le pataúa est frère du bacaba." [7]

"Les jutaípeuá, jutaípororoca, jatobá doivent être de la même famille car ils produisent

la même résine" [4] 
"Le tenteiro amarelo et le tenteiro vermelho ont les mêmes fruits, ils sont de la même famille." [3].

17 Ces rapprochements se font également en fonction de critères utilitaires : c'est le cas par exemple de la série des caniceiros qui regroupe trois morphotypes dont les tiges flexibles des jeunes individus servent de cannes à pêche. L'exemple de cette série met en évidence la superposition de critères dans le rapprochement opéré entre les morphotypes. En effet, en plus du critère utilitaire clairement explicité dans le terme de base attribué à ces morphotypes (caniceiro signifiant "canne à pêche " en portugais), la ressemblance des feuilles est aussi mise en avant pour regrouper ces trois végétaux : "Le caniceiro blanc, le caniceiro rouge et le caniceiro noir sont de la même famille, les feuilles sont semblables."[4] ${ }^{5}$. Ces rapprochements entre les plantes varient néanmoins selon les informateurs et leurs connaissances de la morphologie et de l'usage des végétaux. Par exemple, un seul villageois estime que la murteira et la vassoureira sont « de la même famille » ou que le catituzeiro appartient à la «famille du caniceiro ». Un autre informateur affirme que le molongó et le morototó sont « de la même famille " car leurs fleurs et leurs fruits sont semblables, bien que ces deux morphotypes ne soient pas associés chez d'autres personnes interrogées ${ }^{6}$.

18 Ainsi, la variation des critères pris en compte tant dans la reconnaissance que dans la dénomination des plantes par les informateurs locaux (au niveau individuel et collectif) engendre une nomenclature locale riche, comportant une grande plasticité dans les correspondances entre les morphotypes, mais pouvant engendrer des confusions.

19 Au total, 439 morphotypes (arbres, palmiers, lianes, herbes et plantes herbacées) ont été recensés, toutes origines confondues (cf. Annexe pour la liste complète des végétaux, avec leur correspondance dans la taxonomie scientifique). Près de 77 \% des morphotypes (337) se rencontrent exclusivement en forêt de terre ferme (Figure 1).

Figure 1. Distribution des morphotypes - unités de reconnaissance des végétaux selon les villageois - dans les jardins, abattis et forêts

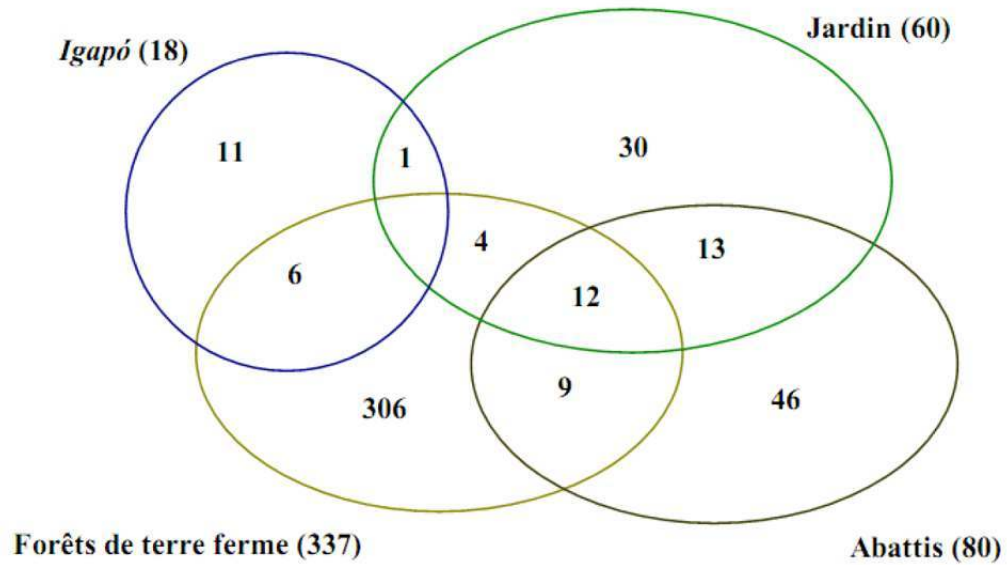


20 L'igapó désigne localement la forêt sur sol hydromorphe. Les « forêts de terre ferme » ne constituent pas une catégorie locale: nous regroupons sous ce terme l'ensemble des formations forestières perçues allant de la juquira à la mata virgem.

Plus de la moitié des morphotypes (56\%) se retrouvent dans des séries regroupant entre 2 et 25 morphotypes. Au total, 257 termes de base ont été relevés (Tableau 1). Une première sélection a permis d'écarter les synonymes quand ces derniers étaient clairement explicités par les informateurs. En revanche, lorsque les noms attribués par les différents informateurs ne se recoupaient pas, les noms des morphotypes ont été cumulés avec le risque que certains d'entre eux soient des synonymes. Dans de rares cas, un morphotype appartenant à une série n'a pas de déterminant bien qu'étant distingué des autres morphotypes de cette série. Dans ce cas là, les villageois précisent généralement qu'il s'agit du « véritable » morphotype (ex : «é o facheiro/abiumesmo »). Seules les variétés de manioc doux connues et nommées par l'ensemble des villageois ont été retenues (4 sur les 12 recensées).

Tableau 1. Nombre de séries et nombre total de morphotypes recensés dans la nomenclature populaire (morphotypes cultivés et forestiers)

\begin{tabular}{|c|c|c|c|}
\hline $\begin{array}{l}\text { A- Nombre de morpho- } \\
\text { types (qualidades) par série }\end{array}$ & $\begin{array}{c}\text { B - Nombre de séries } \\
\text { inventoriées }\end{array}$ & $\begin{array}{l}\text { C - Nombre total de } \\
\text { morphotypes }(A \times B)\end{array}$ & D - Exemples de séries \\
\hline 1 & 193 & 193 & $\begin{array}{l}\text { capitiú, Ferrão de Arraia, caruara, inajá, caiúsará, boa macaca, quiabo, cipó d'alho, } \\
\text { castanha de arara, juquiri, etc... }\end{array}$ \\
\hline 2 & 27 & 54 & $\begin{array}{l}\text { Série de l'envirola : envirola branca/vermeha, } \\
\text { Série de l'ipê : ipê roxo/branco, } \\
\text { Série de l'axuá : axuá da mata/ axuá da beira... } \\
\text { Autres séries : caraîpé, goiaba, jinjá, maracujá, lacre, papaterra, milho (maïs), etc... }\end{array}$ \\
\hline 3 & 18 & 54 & $\begin{array}{l}\text { Série de la fava da mata : fava da mata amarga/branca/vermelha } \\
\text { Série de l'angelim : angelim brinco de princessa/ branco/ pedra } \\
\text { Autres séries : janita, joäo mole, morão, marapuama, Murteira, uruazeiro }\end{array}$ \\
\hline 4 & 4 & 16 & $\begin{array}{l}\text { Série du facheiro: facheiro «mesmow/facheiro vermelho/facheiro preto/facheiro branco } \\
\text { Série de la seringa : seringa do mato/seringa do igapó/seringa nativo/seringa do oriente } \\
\text { Série de la macaxeira : macaxeira boliviana/preta/manteiga/folha fina }\end{array}$ \\
\hline 5 & 6 & 30 & 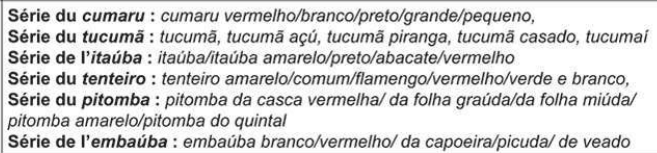 \\
\hline 6 & 2 & 12 & $\begin{array}{l}\text { Série de l'araçá : araçá do jaboti, araçá da praia, araçá pixuna branco, araçá } \\
\text { pixuna vermelho, araçá preta, araçá castanha } \\
\text { Série du taxi : taxizeiro branco/de vara/ fedorento/vermelha/pedra/liso }\end{array}$ \\
\hline 7 & 1 & 7 & $\begin{array}{l}\text { Série du jutaizeiro : jutazeiro grande, jutai miudo, jutaimiri, jutai-peua, jutaiporo- } \\
\text { roca, jutai-jatobá da praia, jutai-jatobá }\end{array}$ \\
\hline 8 & 2 & 16 & $\begin{array}{l}\text { Série du breu : breu amesca,/ breu branco/breu manga/breu pequeno/breu sucu- } \\
\text { ruba/breu vermelho/breurana/breu grande } \\
\text { Série de l'abiu : abiu «mesmow/ abiu cutite/branco/cabeza de macaco/felpudo/ver- } \\
\text { melho/abiurana/abiu liso(=cascadura) }\end{array}$ \\
\hline 9 & 1 & 9 & $\begin{array}{l}\text { Série de la vassoureira : vassoureira/vassoureira vermelho/branca/da folha } \\
\text { grande/alta/ baixinha/da capoeira/da mata/vassourinha }\end{array}$ \\
\hline 10 & 1 & 10 & $\begin{array}{l}\text { Série de l'ingá : ingá branca/ingá cabeludo/ingá comun/ingá corda/ingá da beira/ } \\
\text { ingá da mata/ ingá do macaco/ingá vermelho/ingáxixica/ }\end{array}$ \\
\hline 13 & 1 & 13 & $\begin{array}{l}\text { Série du louro : louro amarelo//branco/vermelho/preto/roxo/rosa/louro da folha } \\
\text { graúda/da folha miüda/bosta/louro itaúba/louro pedra/louro }\end{array}$ \\
\hline 25 & 1 & 25 & $\begin{array}{l}\text { Série de la maniva (manioc amer) : maniva acarizinho/ acarizinho moreno/acari } \\
\text { grande/açaiizinha/ milagrosa/amarela/grande/bem baixa/curuba/três porradas/seis } \\
\text { meses/jamunda/macaco/flecha/tucumä/jaboti/piraiba/bentevi/preta/tartaruzinha/ } \\
\text { mulatinha/urubu/curupira/apetuca/boi }\end{array}$ \\
\hline TOTAL & 257 & 439 & \\
\hline
\end{tabular}

\section{Catégorisation}

\section{Les plantes sauvages et les plantes cultivées}

Le premier critère de catégorisation locale des espèces végétales porte sur la distinction entre espèces plantées (plantas) et espèces "sauvages»( da natureza, ou bravas $\left.{ }^{7}\right)$, ces dernières étant regroupées sous le terme général de mato :

"Cet arbre est sauvage, il appartient au mato" [2]

“Tout ce qui n'a pas été planté appartient au mato." [8] 
“Cela provient (est né) de la nature, c'est du mato." [1]

"Le mato est de la nature, il se forme et grandit tout seul." [9] constitue la strate herbacée et arbustive de la forêt, que ce soit de jeunes recrûs, de jeunes palmiers, des fougères (samambaia), des broussailles (ronces, espinhos) ou des lianes enchevêtrées. En fait, comme le résume un agriculteur : "o mato é todo o que cresce no chão" ("Le mato, c'est tout ce qui pousse au sol"). Le mato est souvent qualifié de «laid» (feio) lorsqu'il est dense en forêt secondaire post agricole - capoeira - (densité traduite, dans le discours local, par la notion de fermeture), par opposition à un sous-bois dégagé (ouverture renvoyant à la notion de propreté, limpo) en mata (forêt mature). C'est d'ailleurs cette différence qui, entre autres, est retenue par les Ribeirinhos pour distinguer ces deux formations forestières. Le mato désigne également les végétaux qui ne sont pas connus, qui n'ont pas de nom, aussi bien en forêt que dans les abattis ("ça, je ne sais pas ce que c'est, c'est du mato" [9]). À noter cependant que, passé un certain stade de croissance (non défini précisément mais correspondant plus ou moins à une hauteur de deux ou trois mètres), le statut de mato n'est plus attribué aux arbres ou aux palmiers. Ces derniers, considérés comme mato au tout début de leur stade de croissance du fait de leur appartenance à la strate arbustive du sous-bois forestier, seront catégorisés, dans un stade de croissance plus avancé, suivant la forme biologique à laquelle ils appartiennent ( árvore/arbre, palmeira/palmier). Ainsi, pour reprendre les propos d'un informateur local : «le mato devient arbre » [2].

Cette transition d'une catégorie à une autre d'une même espèce en fonction de sa morphologie n'est cependant pas aussi nette dans les abattis. Les espèces qui s'y sont développées sans avoir été plantées seront toujours considérées, même une fois adultes, comme des adventices puisqu'elles ont envahi (et continuent d'envahir) un espace domestiqué :

“Dans l'abattis, l'embaúba est mato mais l'embaúba qui est dans la forêt, qui est bien

grand, n'appartient plus au mato." [6]

Cette continuité entre le mato et les arbres structurants de la forêt redevenue primaire ( floresta reformada - forêt reformée - ou mata) apparaît clairement dans le discours des Ribeirinhos, le mato étant parfois synonyme de capoeira, c'est-à-dire une forêt en processus de régénération :

“Tout est mato jusqu'à ce que la capoeira redevienne une mata." [15]

"La capoeira, c'est le mato qui va pousser après l'abattis." [1]

Bien que certaines espèces de mato soient spécifiques aux premiers stades de régénération forestière, la plupart de celles présentes dans les premiers stades de régénération forestière (juquira et capoeira fina) se retrouve dans les forêts secondaires post agricoles plus âgées (capoeiras grossas), seuls variant la taille ou le diamètre de ce mato : 
“ La capoeira fina se régénère (récupère). L'obscurité tue la végétation rampante (la forêt rampante), c'est-à-dire les graminées, le mato, plusieurs espèces d'herbes qui s'utilisent en médecine, [et] qui vont disparaître dans la grosse capoeira. Mais le reste, le mato qu'il y a dans la jeune capoeira va se rencontrer dans la grosse capoeira, sauf qu'ici elles sont fines, ce sont des enfants encore. Dans la grosse capoeira, elles sont adultes, matures. La différence, c'est la grosseur.... " [2] du sauvage dans l'espace domestiqué. L'agriculteur s'applique en effet à ce que les espèces plantées crescem no limpo ("grandissent dans le propre»), en arrachant le mato tout autour. Celui-ci renvoie implicitement à la notion de saleté par opposition à la " propreté », l'ouverture instaurée par l'agriculteur dans son abattis suite aux diverses tâches de désherbage effectuées (que les agriculteurs eux-mêmes désignent sous le terme limpeza, «nettoyage »). Néanmoins, de jeunes individus poussant spontanément dans l'abattis peuvent être finalement conservés et valorisés (au sens large, et pas seulement d'un point de vue commercial) par l'agriculteur, délaissant ainsi leur statut de mato pour celui d'espèces domestiquées (plantas) et cultivées puisqu'elles reçoivent les mêmes soins de nettoyage et d'élagage que les autres espèces pérennes ou annuelles plantées. Il s'agit alors d'espèces valorisées soit :

- pour leurs fruits : elles sont alors qualifiées de mato de comer (mato comestible) telles que l'ingá ou le bacaba

- pour leurs propriétés médicinales : ex : andiroba, piquiá, sucuúbeira, copaibarana, 
- pour leur bois : ex : lacre, mogno,

- pour l'artisanat : ex : envira,

- pour l'ombre qu'elles procurent dans l'abattis, voire pour des raisons esthétiques.

"Un mato qui a reçu des soins est comme une plante... Le mato est devenu une plante." [3]

"Le copaibarana appartient au mato de la forêt ici. On le laisse se développer tout seul et il devient mato avec le mato d'ici. Si on le cultive, il devient une plante. Quand j'ai cultivé cette sucuúbeira, ce n'était pas un mato. Elle est apparue (est née) rapidement après que l'abattis a été brûlé. Quand on a commencé à retirer les mauvaises herbes, on ne l'a pas arrachée, on l'a laissée pousser. On a seulement retiré le mato près d'elle. Maintenant, nous la considérons comme une plante, car elle a bénéficié de nos soins. Je vais nettoyer de temps en temps autour d'elle pour qu'elle grandisse plus rapidement. Cette sucuúbeira, nous l'utilisons seulement pour notre propre consommation." [3]

31 Ainsi, l'agriculteur trouve légitime de s'approprier les arbustes, arbres ou palmiers poussant spontanément dans son abattis à partir du moment où il apporte ses soins à ces derniers. L'analogie faite entre l'adoption d'un végétal et celui d'un enfant est courante dans les discours villageois, mettant en évidence une relation symbolique de parenté entre l'homme et la plante dorénavant domestiquée.

“Ce pau d'arco a germé tout seul dans mon abattis. Je l'ai laissé, je ne l'ai pas coupé. Maintenant, je m'en occupe, je nettoie autour de lui (je le laisse dans le propre). Si je m'occupe du fils du pau d'arco jusqu'à ce qu'il devienne un jeune garçon, il devient mon fils. Je ne l'ai pas planté, mais c'est le mien." [4]

Ce changement de catégorie du mato à celle de planta concerne également, dans de plus rares cas, des espèces forestières bénéficiant de soin de désherbage occasionnel de la part de l'agriculteur. Cela a été observé par exemple avec la bacabeira, l'ingazeiro, le jacarandá, le morototó, le parapara, ou la sucuúba.

\section{Catégories englobantes de végétaux}

33 Les Ribeirinhos rattachent les végétaux à des "groupes » ou " ensembles » (également appelés «catégories englobantes" par Friedberg 1986) en fonction de leurs formes biologiques (árvores/paus/arbres, cipós/lianes, palmeiras/palmiers, capim/graminées), leurs morphologies ou stades de développement (palheira et capunga/palmier acaule ou plantule de palmier, taboca/bambou, paus de quina/arbres à tronc cannelé...), et de leur utilisation (paus de envira/arbre possédant une écorce interne fibreuse, madeira dura/bois dur, madeira fraca/faible). Certains morphotypes se rattachent à plusieurs « groupes ».

\section{Capim / Les herbes}

Le capim désigne les graminées en général, qu'elles aient été plantées pour l'élévage (dans de très rares cas) ou qu'elles soient «sauvages ». Dans ce dernier cas, elles sont alors considérées comme des adventices, de mauvaises herbes, tout comme le mato. Le capim se distingue cependant de ce dernier sur plusieurs points, à savoir :

- la taille et la forme des feuilles : 
"La feuille du capim est différente de celle du mato. Ce sont des longues feuilles fines. Il y a beaucoup d'espèces (de qualités) de capim, mais la feuille ne change pas, elle est toujours comme ça." [2]

- son mode de croissance :

"Le capim est une chose, le mato en est une autre. Le mato pousse mais le capim reste à ras de terre (rampant), il grandit par le bas [au niveau du sol]..." [3]

- sa plus grande nocivité pour les espèces plantées :

"Le capim va tuer toutes les plantes. S'il y avait du capim ici, ce cupuzeiro serait déjà mort car la terre durcit sous le tronc et la plante n'a pas les moyens de se développer." [3]

- sa plus grande résistance au désherbage :

"Il est plus difficile d'arracher [de travailler avec] le capim que le mato. Quand le capim est présent dans l'abattis, c'est pire que le mato. Quand il pleut, peu après que l'abattis a été travaillé [et] désherbé, le capim va réussir à repousser et le sol va en être rempli. Par contre, si tu arraches le mato, même s'il pleut, il meurt car il n'a pas la résistance du capim." [2]

- ses caractéristiques écologiques et son besoin de lumière :

"Le capim est aussi différent du mato car ce dernier peut survivre à l'ombre mais pas le capim, ou pas longtemps alors : jusqu'à un an quand ce n'est pas encore fermé au dessus de lui." [2]

Les villageois distinguent de nombreux morphotypes de capim : barba de bode («barbe de bouc »), pê de galinha (" pied de poule »), pacuã, pinda, capim amarga (« herbe amère »)... De nombreuses autres espèces ne sont pas nommées et sont simplement désignées sous le terme général de capim.

\section{Espinho et árvores de espinhos / Épineux et arbres d'épineux}

La catégorie des espinhos regroupe tous les végétaux qui piquent ( 0 espinho fura a gente ») "L'épineux nous pique »). Elle recoupe celles des arbres, des lianes et des palmiers et forme en fait une sous-catégorie de ces dernières plus qu'une catégorie en soi. Les villageois distinguent en effet les «lianes épineuses» (cipós de espinho), les «arbres épineux » (árvores de espinho), et également les « palmiers épineux » (« o mumbacá é espinho tipo palmeira »/«Le mumbacá est [un] épineux du type palmier» [2]) :

"Il y a la liane épineuse et il y a l'arbre épineux. C'est une autre famille. Il y a le japecanga et le mimorama qui sont des espèces épineuses. Il y a le jurubeba et la tamanqueira aussi qui sont des arbres épineux qui poussent haut. La samaumeira possède des épines aussi mais seulement quand elle est jeune, jusqu'à cinq ou six ans. Quand elle devient adulte, les épines tombent (sortent)..." [2]

Les Ribeirinhos reconnaissent de nombreux espinhos même s'ils ne les nomment pas tous :

"Il y a beaucoup de races d'épineux dans la forêt, que ce soit des lianes ou des arbres d'épineux... Il y en a de nombreuses autres qui ont des épines [et] qu'on ne connaît même pas." [2]

De plus, les espèces considérées espinho recoupent également la catégorie du mato car ce sont des espèces considérées envahissantes voire nuisibles.

\section{Palmeiras, palhas et capungas / Palmiers}

Parmi les palmiers (au sens botanique), les Ribeirinhos distinguent les palmeiras des palheiras (ou palhas) en fonction de l'existence ou non de stipe, ou de la hauteur de celuici. Ainsi, un palmier n'ayant pas de stipe tel que la curuá n'est jamais considéré comme palmeira mais comme palheira. De même, les espèces ayant un stipe de faible hauteur 
(lorsque les individus sont encore jeunes) sont catégorisés palheiras. En revanche, une fois que le stipe aura atteint environ un mètre, les végétaux seront considérés comme des palmiers à part entière (palmeiras). Avant de devenir palheira, la plante passe par le stade capunga. Le terme capunga est attribué aux feuilles entières des plantules (« Les premières feuilles naissent capunga ») puis, par extension, à la plantule elle-même. Lorsque les folioles commencent à s'ouvrir, les palmes sont alors nommées palhas pretas (" palmes noires ») et la plante devient palheira. Ainsi, les termes capunga, palheira, puis palmeira (dans le cas des espèces formant un stipe) sont utilisés pour nommer une même plante à des stades de croissance différents (Photographies 2 à 4). Les plantes différemment nommées sont de ce fait considérées comme étant de la même qualidade (espèce) ou de la même « famille ».

"La palha de curuá tarde un peu à pousser : elle pousse d'abord comme capunga les deux, trois premières années. Ce n'est qu'après qu'elle se développe comme palha. La capunga est de la même famille, de la même espèce que la palha." [3]

"La curuá naît capunga. Elle reste capunga quand elle est jeune. Quand elle grandit, les feuilles se séparent [ndl : feuille composée] et elle devient palheira. Il y a aussi la capunga de l'inajá, qui est comme celle de la pupunheira mais ces deux espèces sont des palmeiras [ndl: elles vont former un stipe] alors que la curuá est une palheira [ndl : absence de stipe même au stade adulte]. Quand la curuá meurt, elle meurt palheira. Le tucumã, l'inajá, la pupunha non: ils naissent capungas et meurent palmeiras." [13]

Photographie 2. Capunga de curuá (Attalea attaleoides)

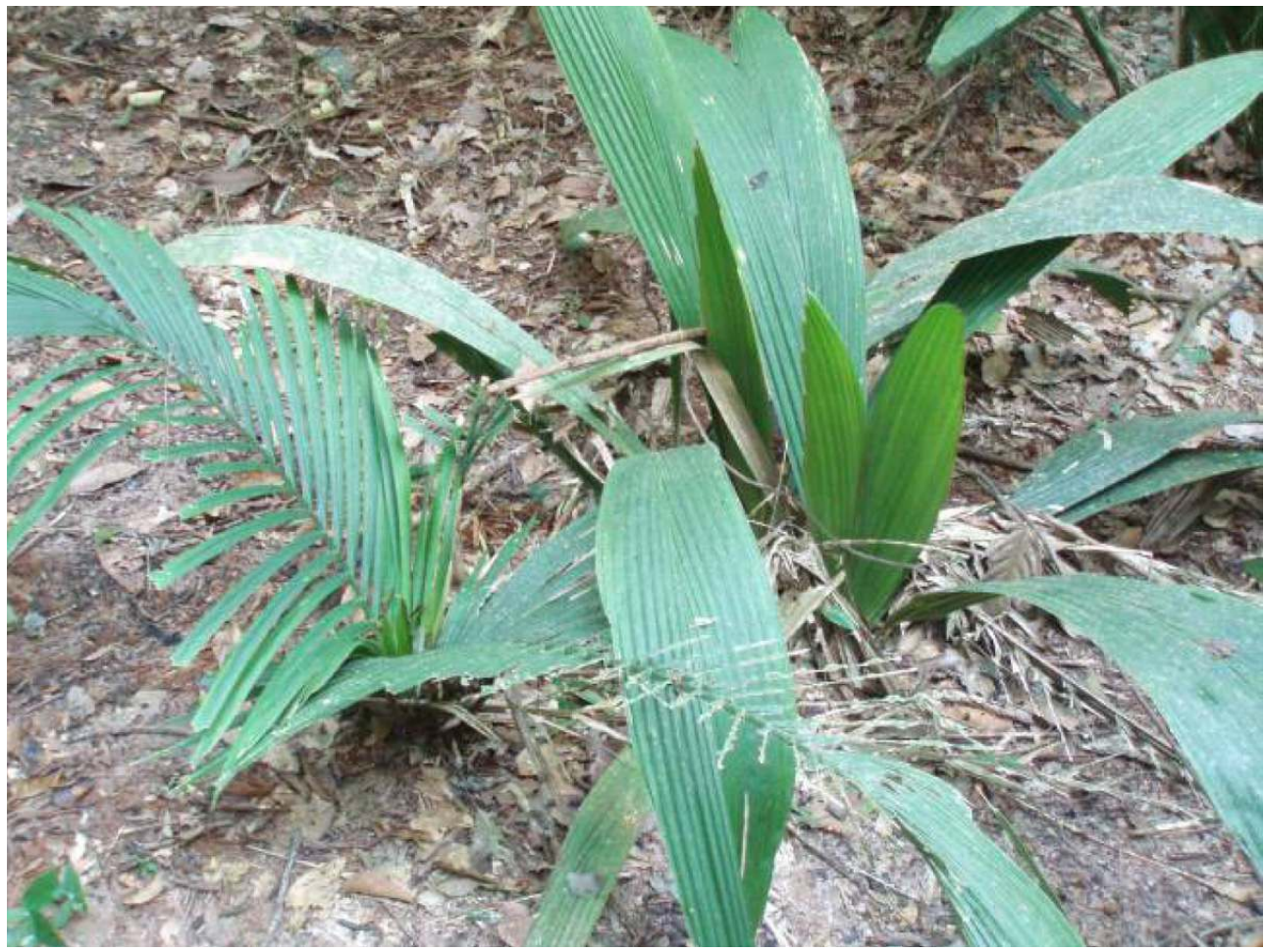

En arrière plan (plantule avec les feuilles entières) et juvénile en premier plan, avec les feuilles composées (déjà palheira)

C. Couly 
Photographie 3. Palmier adulte acaule : palheira d'Attalea attaleoides

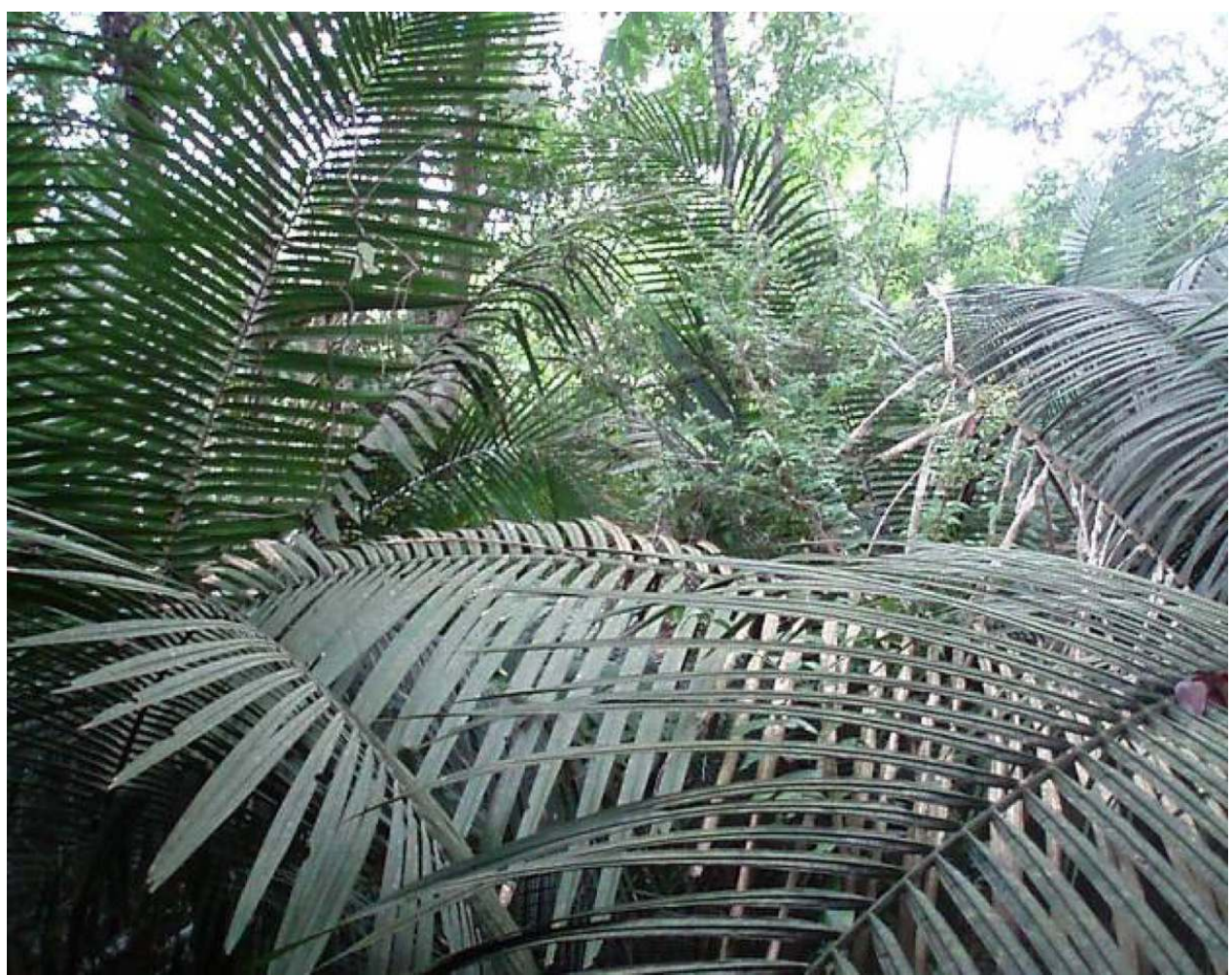

C. Couly

Photographie 4. Palmiers avec stipe : palmeira

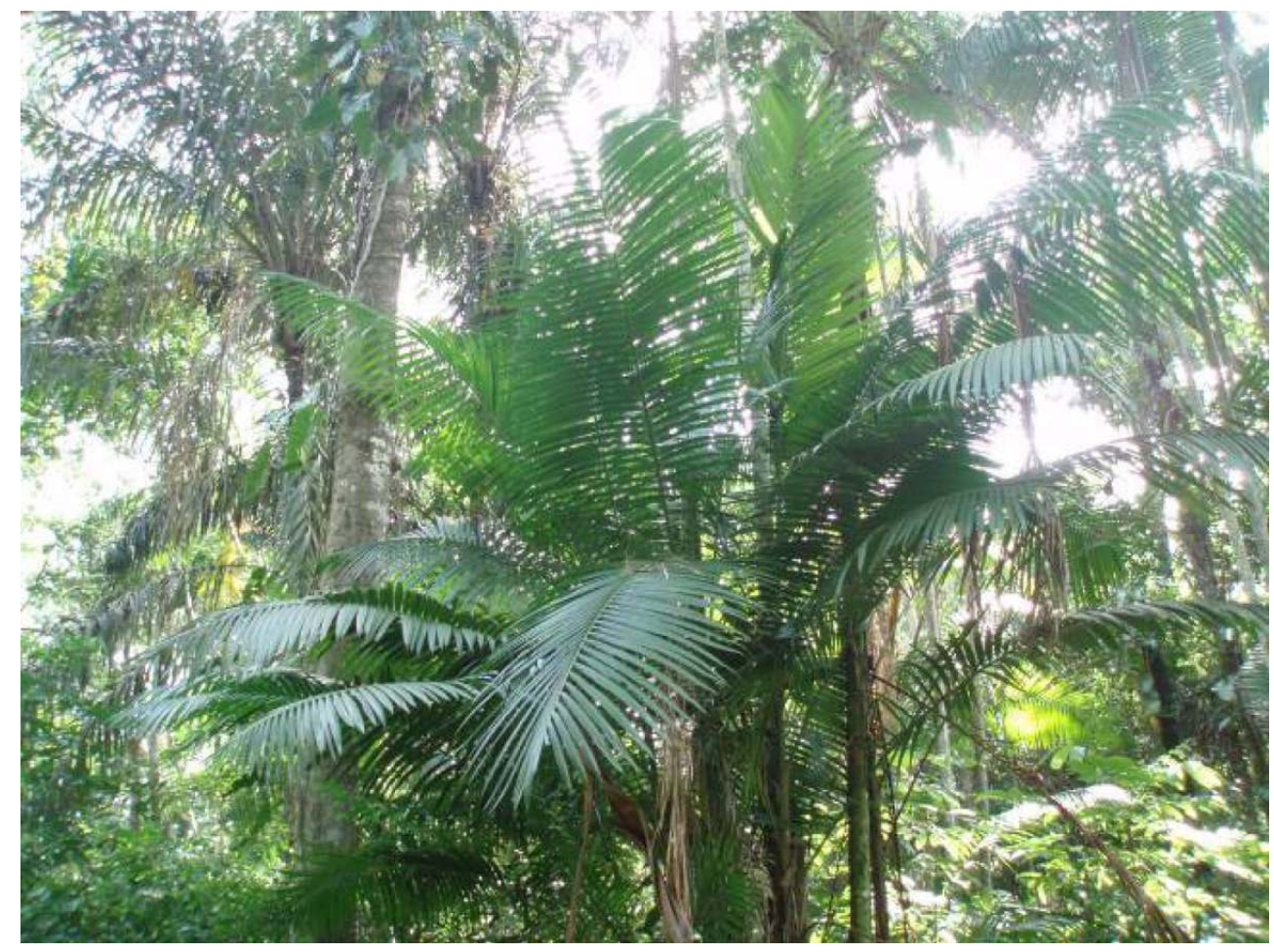

C. Couly 
distinction entre les arbres (árvores ou paus) et les palmeiras ne s'exprime pas nettement dans le discours des Ribeirinhos. Il est en effet fréquent que les palmiers soient explicitement nommés et catégorisés comme étant des arbres (ex: "Le tucumã est un arbre, un palmier, c'est pareil..." [6], "les arbres comme l'açaí, le bacaba..." [2]). La catégorie des arbres inclut donc plus largement l'ensemble des végétaux ayant des axes non ramifiés. Les termes toco et caule sont d'ailleurs utilisés localement pour désigner de façon générale des axes non ramifiés que ce soit les troncs d'arbres ou les stipes des palmiers. Seul le terme tronco est employé pour désigner le tronc lignifié des arbres. confirme le fait que le chevauchement des catégories palmeiras et arbres tient à l'existence d'un axe non ramifié.

"Quand il est mature, le tucumã est un arbre. Au début, c'est une sorte de palha. Ensuite, il va grandir. Ces branches [en fait, la base des palmes] vont s'unir pour former son stipe." [6]

La classification d'une plante peut aller plus loin en faisant intervenir une troisième catégorie. Cela s'est observé notamment dans le cas d'un palmier épineux, dénommé localement mumbaca, lorsqu'un villageois l'a désigné spontanément en affirmant : «c'est un épineux, c'est une sorte de bois ». La catégorie de palmeira n'a donc pas été explicitée, soit parce qu'elle était sous-entendue, soit parce que cette plante a été catégorisée en premier lieu par rapport à la présence caractéristique d'épines, et ensuite, par la présence d'un axe non ramifié la rattachant à la catégorie générale d'arbre.

Malgré cette forte association des palmeiras aux arbres, les Ribeirinhos les distinguent néanmoins de ces derniers selon d'autres critères tels que la présence de palmes et non de feuilles ("Le jauarizeiro est un arbre qui a des palmes..."[2]), l'absence de bois " ("Il n'y a pas de bois dans la piririma, c'est un palmier"[3]) et d'écorce interne fibreuse ("Les palmiers n'ont pas d'écorce interne fibreuse. Ils ne forment pas de rejet du stipe si on les coupe."[2]) ou, au contraire, la présence d'une moëlle ("La différence entre un palmier et un arbre, c'est que le palmier possède un cœur de palmier à l'intérieur."[6]). Le regroupement des palmiers dans une catégorie distincte de celle des arbres se traduit ici encore par l'appartenance à une même famille: "La mumbaca, le tucumã, le bacaba, le cocotier appartiennent à la famille du palmier" [5], "La piririma est un type de palha; elle est de la même famille que la curuá" [2].

Outre les espèces précédemment citées (tucumã, muúbaca, inajá, jauarizeiro, bacabazeiro, côcozeiro..), on retrouve également dans cette catégorie le palmier pupunheira, açaí, patauá, burutizeiro, jará...

\section{Taboca / Bambou}

Le terme taboca désigne à la fois un arbre (taboca da mata, aussi appelé tabocão par certains informateurs) et un bambou (taboca ou taboca fina) qui, lui, est généralement planté.

Ces deux morphotypes, bien que désignés par le même nom, sont néanmoins associés à des catégories différentes, le taboca fina étant clairement distingué du groupe des arbres et rattaché à la catégorie même de bambou ("La taboca plante n'est pas du bois, c'est un bambou”). Cette catégorie est elle-même une sous-catégorie des palmiers du fait de son absence de bois, mais se distingue de ces derniers par son chaume fistuleux cloisonné en nœuds : 
“La taboca est une sorte de palmier sauf qu'à l'intérieur il est creux, c'est un type de bambou. Il pousse dans les endroits laids. Il est très coupant."[13] bois ») des non ligneuses, désignées comme étant "molles»). Ils distinguent parallèlement deux types de lianes en fonction de leur mode de croissance : les lianes grimpantes qui germent au sol puis grimpent en hauteur (cipós trepadeiras, définies localement comme étant "les lianes qui vont de bas en haut»), et celles qui germent en hauteur sur les branches des arbres et lancent leurs racines au sol (c'est-à-dire, selon les termes écologiques, celles ayant une croissance hémi-épiphyte: exemple de l'erva de passarinho " herbe du petit oiseau »- ou de l'apui). Les lianes appartenant à ce deuxième groupe ne sont pas désignées par un terme particulier caractérisant leur croissance, ce sont simplement des cipós. Les racines qui descendent et s'ancrent au sol sont considérées comme étant les «fils de la liane-mère " située au niveau de la canopée, où elle déploie ses feuilles, fleurit et fructifie ("C'est la liane qui retient la mère tout là haut, [celle] qui donne les feuilles et les fruits, comme la liane taracuá." [15]). Les Ribeirinhos énumèrent de nombreuses lianes grimpantes (trepadeiras) : peroba, maracujá, rabo de cameléão, cipó tinga, cipó açul, cipó titica, cipó escada de jaboti, etc...

51 Parallèlement, ils distinguent les lianes en fonction de leurs stratégies de survie : les « lianes qui tuent leur hôte » et celles considérées inoffensives qui constituent la grande majorité des lianes grimpantes (trepadeiras). Ces dernières correspondent, au point de vue écologique, aux épiphytes. Entre ces deux catégories, les Ribeirinhos distinguent aussi les lianes " parasites », qui ne tuent pas leurs hôtes mais vivent à leurs dépends : 
"Le parasite ne tue pas l'arbre. Il tire (utilise) seulement [son] alimentation [la sève] de l'arbre pour être beau. Il se maintient à l'écorce car c'est de l'engrais pour lui." [15]. faite en écologie entre les parasitoïdes (parasites qui, au cours de leur développement, tuent systématiquement leurs hôtes) et les commensaux («parasites » qui se nourrissent de matières organiques produites par l'hôte sans dommage pour ce dernier) ${ }^{9}$.

Dans la première catégorie, on trouve donc l'apuí ou apuízeiro, figuier étrangleur (Photographie 5), mais également l'erva de passarinho. Les discours recueillis auprès des Ribeirinhos sur la stratégie de vie de ces plantes sont riches et détaillés, notamment pour l' apuí. Quel que soit l'informateur, ces propos décrivent toujours la compétition entre la liane et son arbre hôte comme une lutte entraînant la mort de ce dernier. Celle-ci résulte d'un transfert de la force de l'arbre hôte vers l'apuí (« l'apuí puise la force de l'arbre »), et d'un affaiblissement progressif de l'arbre («l'apuí tire la résistance de l'arbre »). Cette liane prend alors la place de celui-ci («prend possession de l'arbre »), incorporant son bois (" prend possession du bois de cœur de l'arbre ») jusqu'à devenir lui-même arbre : il quitte alors son statut de liane pour celui d'arbre à part entière («la liane devient arbre »). Parallèlement, il tire sa force du sol et des racines de son hôte («tire la résistance de la terre »). En prenant possession du bois de cœur de l'arbre hôte, l'apuí prend la place de l'hôte non seulement physiquement mais également symboliquement en lui prenant sa force et en incorporant son identité d'arbre. Certains informateurs catégorisent cependant l'apuí déjà comme arbre dès sa germination puisque la majeure partie de son cycle de vie se déroule dans la canopée et que seules ses racines descendent jusqu'au sol («L'apuízeiro est un arbre, il se développe au dessus. »[2]). Des comportements moraux et humains servent également à décrire le comportement des plantes : un villageois a ainsi qualifié l'apuí de « lâche » car il tue ses hôtes pour survivre, le jugeant comme s'il s'agissait d'une personne. 


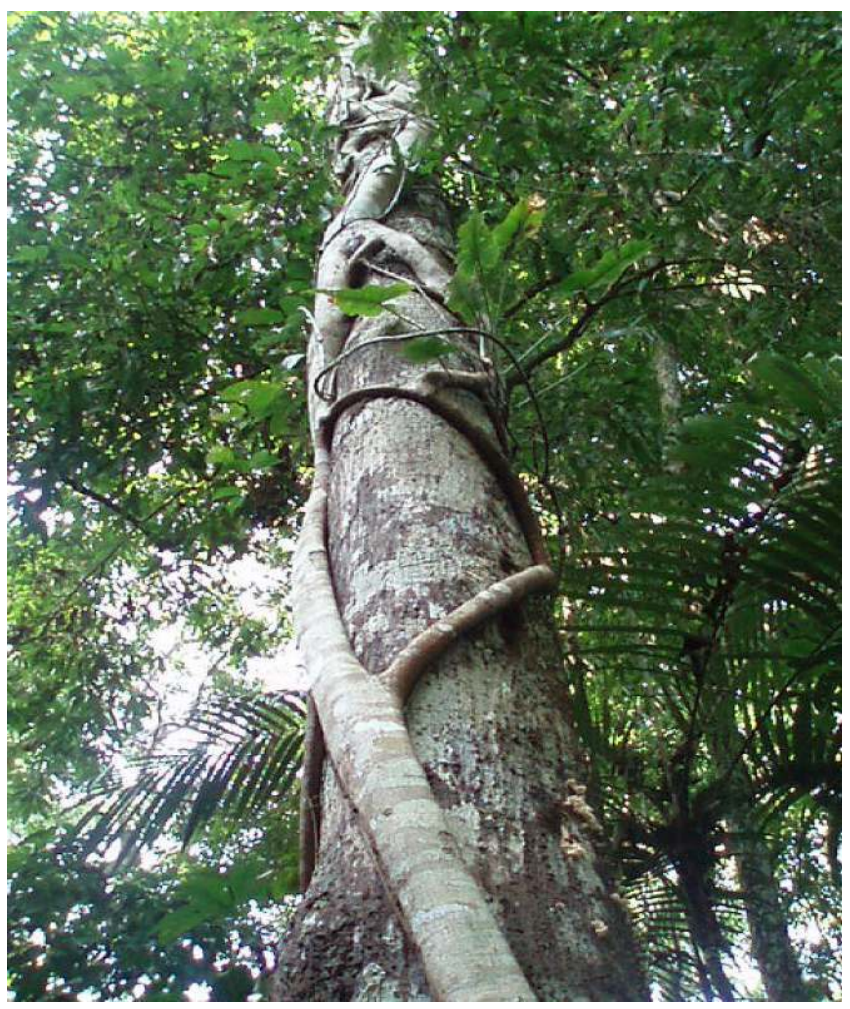

C. Couly

Parallèlement à sa classification de liane tueuse (« qui tue l'arbre ») et à sa distinction des lianes dites parasites, l'apuí est également considéré comme étant opportuniste (cipó aproveitadora) du fait qu'il tire parti des faiblesses de certains arbres pour s'y développer. Cela concerne notamment les arbres creux, plus faciles à dominer :

"L'apuí est une liane opportuniste. Il s'en prend (profite) aux arbres décomposés ou creux afin de les dominer. Il entre à l'intérieur [et] profite du bois qui se décompose. Il recouvre l'arbre entièrement, [et] devient alors de la grosseur de celui-ci. Il ne monte pas dans les arbres qui ne sont pas creux. L'apuí aime se développer (se donner) sur la cuiarana, sur l'atarizeiro, sur l'itaúbarana. Par contre, il est difficile de trouver l'apuí sur le piquiázeiro, le cumaruzeiro, l'andiroba, le taperebazeiro parce qu'ils [ces arbres] ne sont que rarement creux..." [15]

"Il y a des arbres creux vivants tels que la maracatiara. Ce dernier reste vivant en hauteur [au niveau du houppier]. C'est cette hauteur que l'apuí aime. Il voit qu'il ne meurt pas, entre en lui puis le tue. Si on peut apercevoir une feuille d'apuí, cela veut dire que l'arbre est creux. Cela ne vaut pas le coup alors de l'abattre. L'apuí n'aime pas le taperazeiro car son bois est tendre (mou), cet arbre est rarement creux. Mais s'il y a une maracatiara à côté, remplie de fissures (trous), il préfère." [13]

Dans leurs discours, les villageois attribuent une intentionnalité à l'apuí tant dans la sélection de son hôte (« choix » du plus vulnérable) que dans sa stratégie de survie («tuer l'arbre pour prendre sa place »). La stratégie de l'erva de passarinho est similaire à celle de l'apuí, selon les Ribeirinhos, car elle tue également son hôte pour survivre. Cependant, à la différence de l'apuí, elle ne se lignifie pas et « ne prend pas possession » de l'arbre mort. De ce fait, elle ne change pas de catégorie et reste toujours cipó (liane).

"L'herbe du petit oiseau est une liane qui tue aussi : elle tire la force de l'arbre et tue en tirant l'eau présente dans l'arbre." [7] 
"L'herbe du petit oiseau s'appelle ainsi car l'oiseau mange le fruit de petite taille de cette herbe et dépose ses excréments sur un autre arbre, où la graine va germer. Quand elle devient grande, elle tue l'arbre car elle est plus forte. Elle s'enroule autour [de l'arbre], et le tue (prend sa vie) : l'arbre sèche et arrête de fructifier. Elle tue car elle ne sait pas où déployer ses feuilles, car la force de l'arbre vient de la racine et des feuilles. La feuille de l'arbre est la vie de l'arbre." [15] des lianes, des espinhos ou même des herbes (capim). En effet, les espèces appartenant à ces trois dernières catégories (dont l'une peut être considérée comme une sous-catégorie des deux précédentes, comme nous l'avons vu) sont souvent associées à des espèces envahissantes, et sont de ce fait rattachées au mato. Hormis des changements de catégories pouvant être opérés pour certaines plantes, il a également été relevé, dans le discours d'un villageois, le cas d'une transformation d'un végétal en un autre végétal ( mudança de qualidade), au sein d'une même catégorie de plantes. C'est le cas particulier de la liane taracuá qui se transformerait en liane ambé au cours de sa vie (toutes deux des Philodendrons).

"La taracuá devient ambé. Elle naît d'abord taracuá et devient ensuite liane ambé. La liane taracuá va pousser en s'accrochant à l'arbre. Ensuite, elle jette (envoie) la racine au sol. Elle provient de la même graine sauf qu'elle change d'espèce (qualité)." [14]

61

Revue d'ethnoécologie, 3 | 2013 
feuilles de la liane escada de jaboti (Photographie 6), leur forme et leur couleur étant similaires à ces dernières. L'insecte serait lui-même engendré par la transformation d'une jeune liane, bien que le doute sur son origine soit clairement explicité :

"Les ailes de la mante religieuse proviennent de la liane. Ce sont les feuilles de la liane. Je connais seulement celle-ci [de sauterelle] qui provient d'une liane comme ceci, je n'ai jamais vu cela avec un autre [insecte]. Par contre, je ne sais pas si ellemême [la mante religieuse provient de la liane. Ça doit être le cas... Elle doit naître (jaillir) de celle-ci [de la liane].”[7]

Photographie 6. Lianes cipó escada de jaboti (Bauhinia sp.)

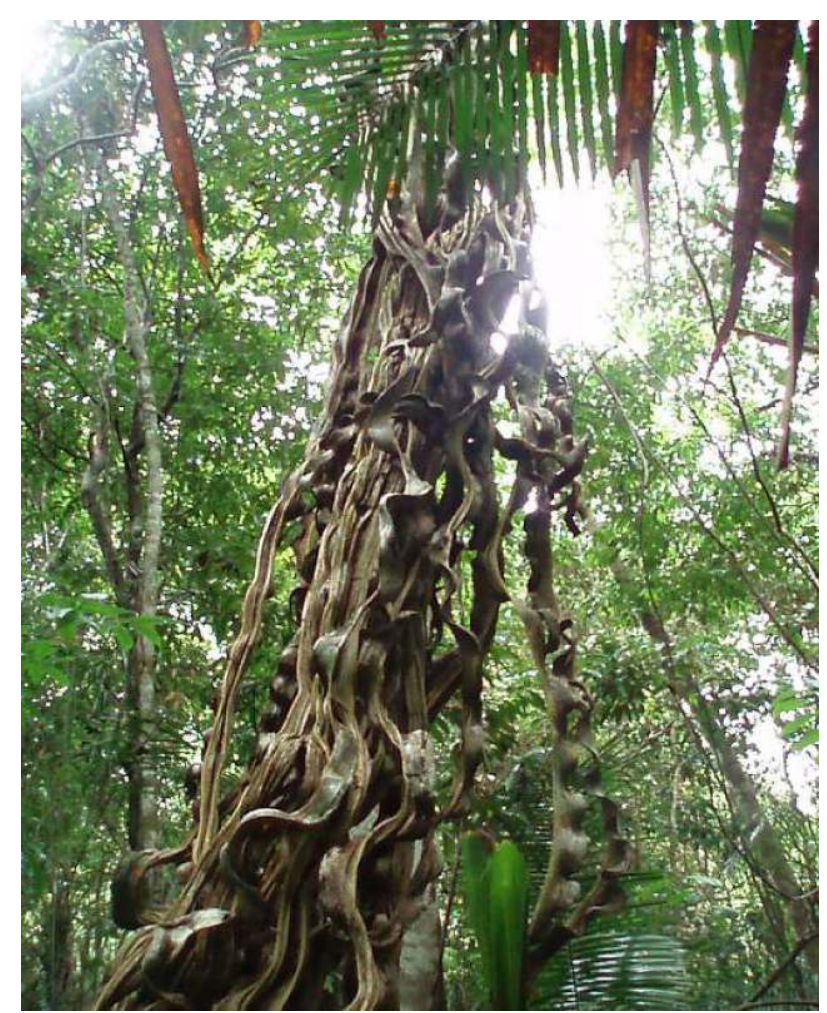

C. COULY

\section{Paus - Árvores}

62 La catégorie des arbres (paus ou árvores) est elle-même englobante puisque différentes catégories d'arbres sont distinguées localement et peuvent se recouper entre elles (par exemple: un morphotype rattaché à la catégorie "pau de envira» peut être aussi considéré comme « madeira mole »).

\section{Paus com envira / Arbres possédant une écorce interne fibreuse}

63 La catégorie des paus com envira regroupe l'ensemble des espèces possédant une écorce interne fibreuse (envira) située entre l'écorce et le bois, traditionnellement utilisée par les villageois en guise de corde d'appoint en forêt (pour attacher et transporter un gibier abattu par exemple) ou pour transporter les sacs de manioc ou confectionner des paniers (Photographie 7). Le terme envira désigne l'écorce interne fibreuse en soi mais également deux morphotypes de ce groupe (envira branca, envira preta). La qualité de l'écorce interne fibreuse varie suivant les espèces, celle de l'envira preta par exemple est peu appréciée du 
fait de l'absence de rugosité qui la rend peu résistante (d'où le synonyme d'envira lisa/ écorce fibreuse lisse attribué à ce morphotype). Les Ribeirinhos distinguent deux écorces internes fibreuses assurant chacune une protection de l'arbre mais seule l'envira, l'écorce fibreuse la plus externe, est potentiellement utile, à l'inverse de la seda qui est bien plus fine :

"Il y a plusieurs couches : l'écorce du bois, l'envira, la seda (soie) qui entoure et protège le bois (c'est une envira plus faible qui craque (éclate) plus facilement)... En dessous, il y a l'aubier (la chair du bois). Si on tire la seda de l'arbre, celui-ci meurt. Par contre, si on retire seulement l'envira, il n'y a pas de problème si ce n'est pas sur tout l'arbre [toute la circonférence de l'arbre]. Un arbre qui n'a pas d'envira n'a pas [non plus] de seda qui protège son bois mais une espèce d'écorce de bois lisse [à la place]." [2]

Photographie 7. Transport des tubercules de manioc par une villageoise (une écorce fibreuse d' Envira branca sert de courroie de portage)

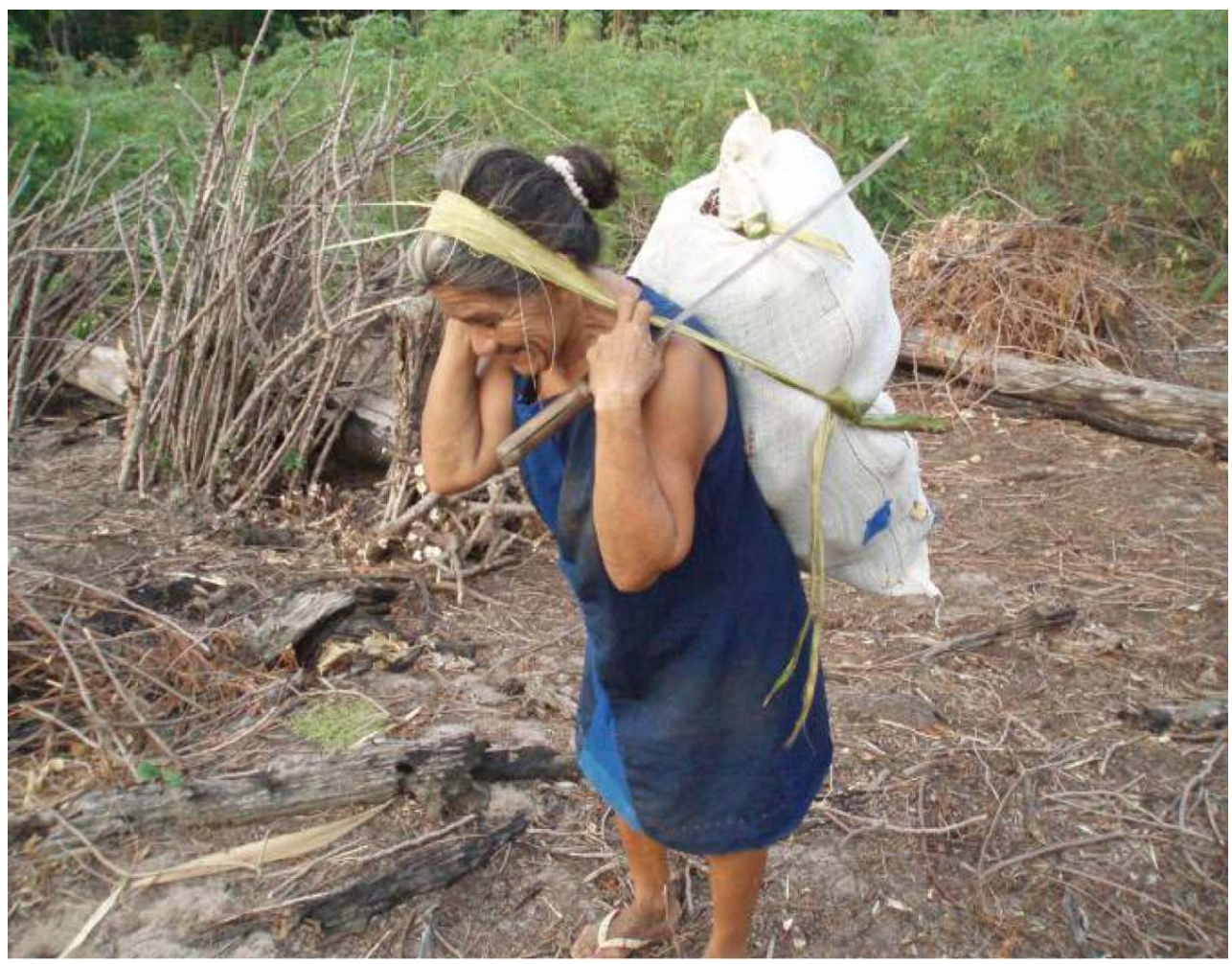

c. COULY

Cette catégorie regroupe le morão, l'aquiquizeiro, le facheiro, l'envira branca, l'envira preta, la piririqueira, le tauari.

\section{Madeira mole e madeira dura / Bois tendre et bois dur}

Les Ribeirinhos catégorisent parallèlement les arbres en fonction de caractéristiques du bois telles que la présence ou non d'un duramen ou la dureté du bois. Cette classification se fonde sur la distinction de plusieurs «strates » de l'arbre : casca (l'écorce), sub-casca (partie sous l'écorce), carne da madeira (« la chair du bois », correspondant à l'aubier), et le cerne (le bois de cœur ou duramen). Le terme miolo désigne généralement le duramen de l'arbre mais parfois également l'aubier (il est alors synonyme de carne de madeira, « la chair du bois »). Les Ribeirinhos reconnaissent en effet le rôle du miolo dans la circulation 
de la sève ("C'est le miolo qui prend la substance de la terre pour faire vivre l'arbre »). Or, celle-ci ne circule que dans l'aubier, et non dans le bois de cœur.

Les arbres dont le bois de cœur n'est que peu développé et qui sont donc constitués principalement d'aubier (les Ribeirinhos ont alors coutume de dire, sans doute par simplification, que ces arbres "n'ont pas de bois de cœur») sont considérés comme madeira fraca (« bois faible »), madeira leve ( bois léger ») ou madeira mole (« bois tendre »). L'aubier étant en général plus clair que le duramen, l'appellation de madeira branca (« bois blanc ») est également employée pour désigner les espèces avec peu de bois de cœur, et dont l'utilisation est limitée aux constructions temporaires (d'un an en moyenne).

"Les arbres que l'on appelle bois blancs sont ceux qui n'ont pas de bois de cœur.

C'est seulement quand ils grossissent qu'ils commencent à former le cœur."[2]

"Il est rare que le bois blanc ait un bois de cœur mais la tapiririca, l'abiurana, la

pororoqueira, le capitiú, le morão sont des bois blancs et ont un bois de coeur."[2]

Les arbres possédant un duramen développé sont dénommés et catégorisés madeiras duras (bois dur) ou madeiras seguras (bois résistants). Ils correspondent en partie aux arbres considérés madeiras de lei ce dernier terme étant employé par les Ribeirinhos dans un sens large pour désigner les arbres de grande valeur pour leur bois, servant à la fabrication de meubles ou des pièces maitresses d'une charpente (telles que les piliers de soutien ou esteios), voire même de pirogue. Ce terme de madeiras de lei désigne donc, en français le "bois d'œuvre". La valeur économique marchande de certaines de ces espèces est connue par la population locale mais, la vente de bois étant formellement interdite au sein de la forêt nationale, l'appellation locale de madeira de lei renvoie avant tout aux espèces recherchées par les villageois pour la réalisation des travaux de construction. Les villageois savent que certaines des espèces dites madeira de lei sont également protégées au niveau législatif, et donc interdites à l'abattage. Ainsi, par extension, ce terme regroupe, dans son sens local, l'ensemble des espèces traditionnellement exclues de l'abattage.

“Ce que nous appelons ici madeira de lei, c'est le bois que l'on ne peut pas abattre. Ce ne sont pas tous les arbres qui sont madeira de lei. Ici, pour nous, madeira de lei, c'est le cumaru, les palmiers..." [7]

Il y a cependant des exceptions à cette séparation faite entre madeira dura/segura (bois dur/résistant) et madeira fraca/mole (bois faible/tendre). Certaines madeiras brancas sont en effet reconnues comme ayant un bois tout aussi résistant que celui des madeiras duras et sont par conséquent valorisées dans la construction des pièces de charpente de longue durée de vie. Elles sont donc madeiras brancas (absence de duramen développé) tout en étant considérées madeiras duras/seguras (bois résistant). Cette bonne qualité de bois est due, selon les villageois, à la présence d'« huile» (une oléo-résine) ayant des propriétés insectifuges qui empêchent la dégradation du bois après sa coupe.

“Tous les arbres qui ont un bois de cœur sont durs. [Mais] plusieurs arbres sans bois de cœur sont [aussi] très durs, [même si] ce sont des bois blancs: fava amarga, itaúba, maçaranduba, maparajuba. Tous les bois blancs ne sont donc pas faibles."[4] "L'andiroba n'a pas de bois de cœur mais c'est son huile qui rend le bois résistant, qui empêche les insectes «perceurs" de manger le bois. L'andiroba résiste un bon temps une fois coupé car il ne pourrit pas grâce à l'odeur de l'huile du bois qui ne laisse pas passer les insectes. C'est pour cela que l'on peut l'utiliser longtemps dans la maison. La copaíba possède également une huile qui la rend résistante. Le paraparazeiro est différent (autre), il n'a pas d'huile, c'est un bois faible, il n'a pas de bois de cœur" [2] 
69 À l'inverse, certaines espèces ayant pourtant un duramen développé ne sont pas valorisées dans les travaux de construction du fait de la rapide altération du bois causée par des facteurs biotiques externes (termites) ou par une faible résistance à l'humidité ambiante :

"Il y a des arbres qui ont un bois de cœur, mais qui sont tendres car ils se décomposent rapidement une fois abattus, surtout l'hiver [saison des pluies] lorsque c'est humide, comme le taxizeiro."[2]

"La tapiririqueira lorsqu'elle atteint vingt ans va développer un duramen mais elle ne sera jamais un bois de valeur (madeira de lei) car [son] duramen est faible."[2].

\section{Espécies nativas / Espèces natives}

Les Ribeirinhos distinguent les espèces dites « natives » (espécies nativas) des espèces « non natives ». Les premières correspondent aux espèces indigènes («qui sont dans la forêt depuis le temps des Amérindiens ») et sont caractérisées par l'absence de l'intervention de l'Homme dans leur reproduction («Les espèces natives n'ont pas été greffées, elles germent (naissent) de la graine »). À l'inverse, les espèces «non natives » sont celles qui ont été introduites et qui doivent être greffées sur d'autres individus pour croître et se développer, telles que la seringa do oriente (hévéa oriental, également appelé seringa americana), traditionnellement greffée sur l'hévéa "natif» (Photographie 8), ou les citronniers. Plus généralement, l'ensemble des espèces plantées mais non greffées sont considérées comme des espèces « natives » par les Ribeirinhos puisqu'elles proviennent de la germination des graines, et ce, même si certaines d'entre elles ne sont pas originaires d'Amazonie (exemple de l'oranger ou du papayer...). Le fait qu'une espèce soit considérée comme originaire ou exotique dépend de l'échelle de temps prise en compte : si l'espèce a été introduite il y a plusieurs générations, elle est considérée comme étant une espèce indigène et donc "native ». Les espèces dites "natives » sont également qualifiées de « définitives ", de "fortes » et de "résistantes ", à l'inverse des espèces "non natives » considérées «faibles ». Ces notions de force et de faiblesse des plantes font référence à leur capacité de résistance à la sécheresse, et par conséquent, à leur durée de vie :

“L'arbre natif ne meurt pas, il résiste beaucoup jusqu'aux petits-fils et arrièrepetits-fils..." [7]

"Les espèces natives sont des espèces définitives, elles vivent (durent) de nombreuses années."[5]

"Les arbres itaúba, breu, cajueiro sont natifs. On dit que l'hévéa est natif car ses fruits tombent et [les graines] naissent. Mais il y a aussi [des arbres] qui ont été plantés que l'on appelle natifs car ils n'ont pas été greffés. Les plantes natives sont plus fortes, elles résistent. Celles qui ont été greffées meurent rapidement. Il y a des hévéas greffés et d'autres natifs aussi." [9] 
Photographie 8. Agroforêt d'hévéas près du village d'Acaratinga (Forêt nationale du Tapajós)

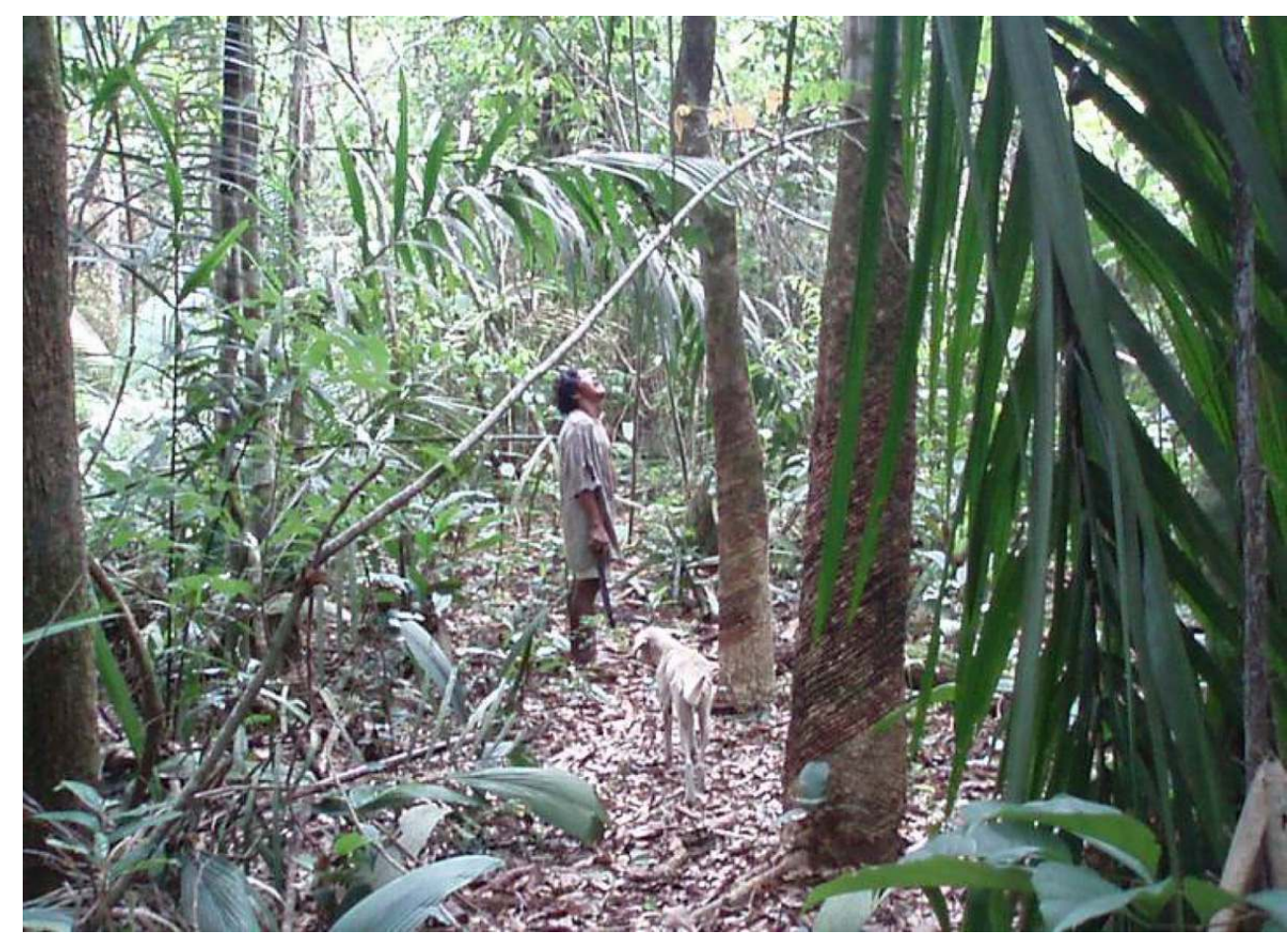

C. Couly

\section{Paus de quina / Arbres à tronc cannelé}

71 Cette catégorie regroupe tous les arbres ayant des troncs cannelés, qualifiés localement de quinas («Cet arbre à feuilles larges est quina. »). Cette catégorie se forme donc clairement sur des critères morphologiques et constitue une sous catégorie des paus ou á rvores (arbres).

Plusieurs espèces sont ainsi considérées quina : la caneleira (ou canela de velho), le jarana, le carapaunabeira et l'acariquara (Photographie 9) qui est sans doute le plus caractéristique. Il est intéressant de noter que même les jeunes individus de ces espèces, n'ayant pourtant pas encore formé leur tronc cannelé, sont tout de même désignés comme étant quina. 


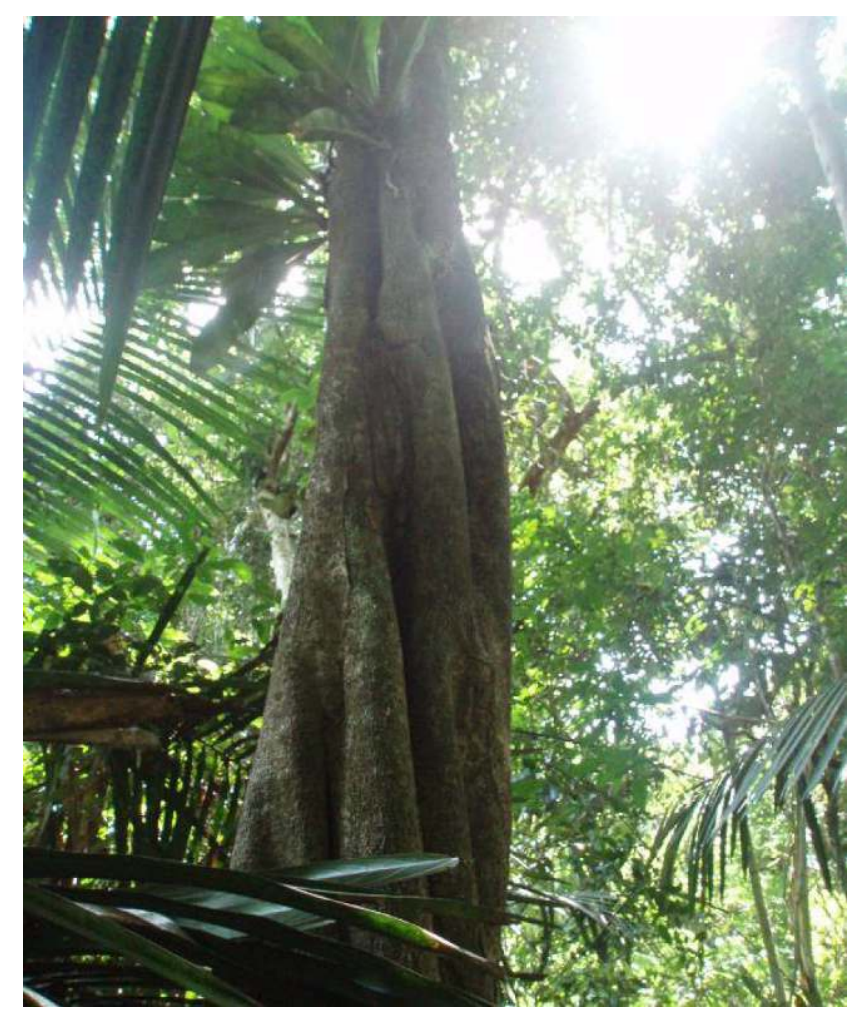

C. Couly

Le nom même pau de quina, correspondant au nom de la catégorie, est parfois attribué en guise de nom provisoire à un quelconque individu ayant un tronc cannelé quand son nom « véritable » n'est pas connu ou du moins oublié.

\section{Nomenclature locale et nomenclature scientifique}

Parmi les 337 morphotypes relevés en forêt de terre ferme ${ }^{10}$ (Figure 1), 206 ont été identifiés ${ }^{11}$ (soit $61 \%$ ) et correspondent à 214 espèces botaniques distinctes (Figure 2 et Annexe). La majorité des morphotypes identifiés fait référence à une seule espèce botanique (158 sur 206 soit $77 \%$ ) mais seule la moitié (110) a une correspondance réciproque exclusive avec cette espèce (catégorie « unique \& exclusive », Figure 3).

Près d'un quart des morphotypes identifiés partagent l'espèce botanique à laquelle ils sont associés avec au moins un autre morphotype («fragmentation »). Les morphotypes uniquement agroupés (cas où un morphotype correspond à plusieurs espèces botaniques) sont moins nombreux, de même que les morphotypes à la fois "agroupés " et «fragmentés» (cas de figure où un morphotype est associé à plusieurs espèces botaniques dont au moins une est désignée en parallèle par un autre nom populaire, Figure 3). 
Figure 2. Identification des morphotypes rencontrés en forêt de terre ferme dans la nomenclature scientifique

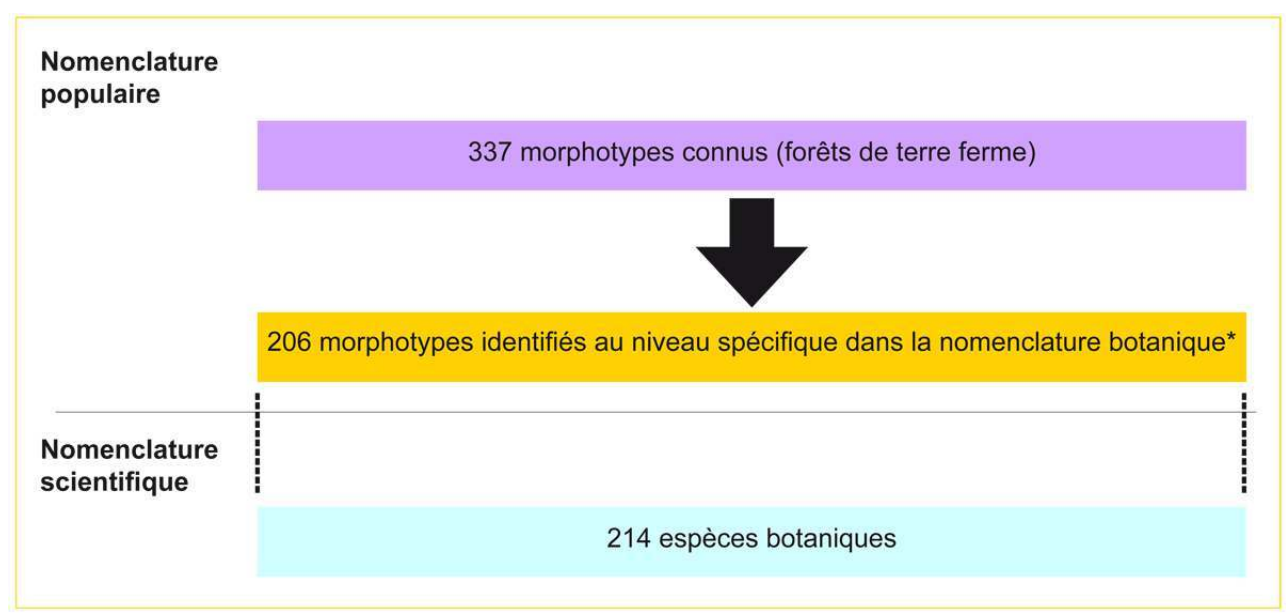

Figure 3. Quantification des variations de correspondance entre la nomenclature populaire et la nomenclature scientifique ( $\mathrm{n}=206$ morphotypes forestiers)

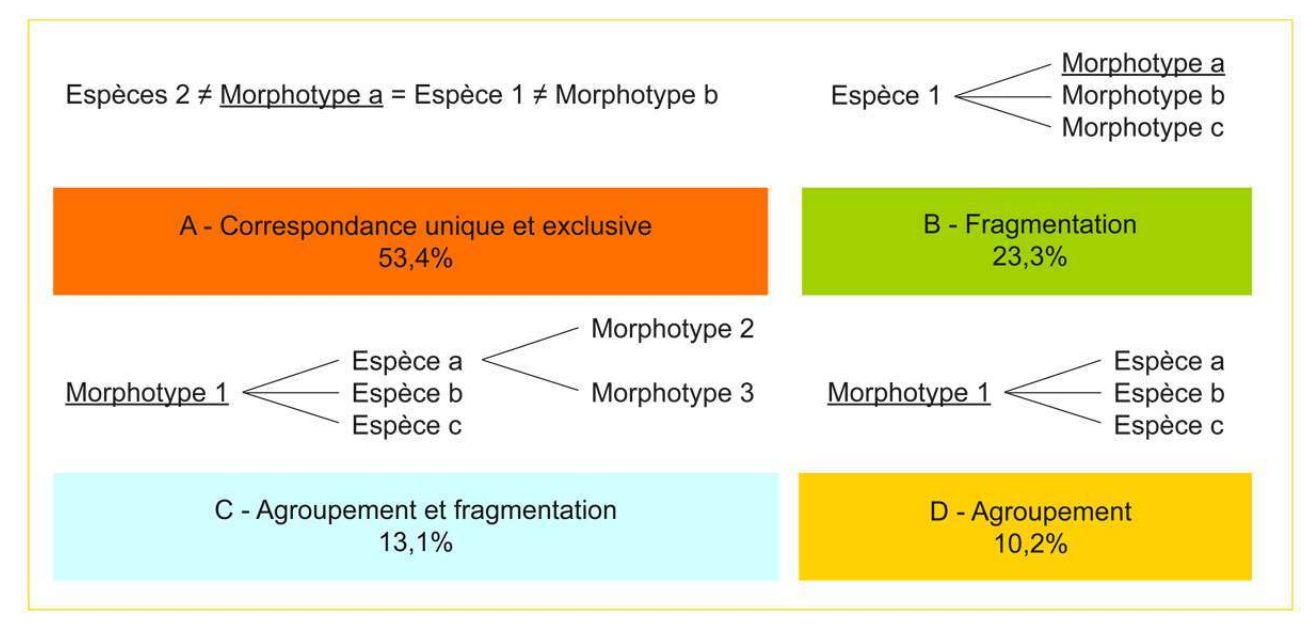

Fragmentation : cas où le morphotype partage l'espèce botanique à laquelle il est associé avec au moins un autre morphotype. Agroupement : cas où un morphotype correspond à plusieurs espèces botaniques (sans que celles si correspondent parallèlement à d'autres morphotypes). Agroupement et fragmentation : cas où un morphotype est associé à plusieurs espèces botaniques dont au moins une est désignée en parallèle par un autre nom populaire

Le pourcentage de morphotypes faisant référence à une seule espèce botanique (mais pas forcément de façon réciproque) est dans cette étude bien plus élevé que celui avancé par Wilkie \& Saridan (1999) dans leurs travaux sur la comparaison des deux taxonomies au Centre de Kalimantan, en Indonésie (entre 12 et $22 \%$ des morphotypes ligneux sont associés à une seule espèce botanique selon les informateurs considérés). Il est aussi bien supérieur aux résultats obtenus par Baraloto et al. (2007), dans un inventaire effectué dans l'Acre ( $50 \%$ des morphotypes ligneux sont associés à une seule espèce botanique) ou lors de la mise en commun de plusieurs inventaires menés dans trois états d'Amazonie brésilienne (moins de $5 \%$ des morphotypes rattachés à la catégorie « unique " parmi les espèces communes aux différents inventaires).

Le Tableau 2 détaille les niveaux taxonomiques correspondant aux agroupements d'espèces dans la taxonomie populaire. Les espèces seulement agroupées (catégorie $\mathrm{D}$ de 
la figure précédente) et les espèces à la fois agroupées et fragmentées (catégorie $\mathrm{C}$ ) sont prises en considération, soit 48 morphotypes au total (23,3\% des morphotypes retenus dans l'échantillon). Près de trois-quarts des cas d'agroupement concernent des espèces appartenant soit à des genres différents de la même famille botanique, soit à des familles différentes (Tableau 2). Ces résultats indiquent une marge de correspondance assez faible entre les deux taxonomies avec d'une part, près de la moitié des morphotypes n'ayant pas de correspondance unique et exclusive dans la taxonomie scientifique, et d'autre part, l'agroupement fréquent d'espèces de genres, voire de familles différentes, pour un même morphotype.

Tableau 2. Niveaux taxonomiques de l'agroupement des espèces botaniques dans la nomenclature populaire ( $n=206$ morphotypes). Agroupement : cas où un morphotype correspond à plusieurs espèces botaniques

\begin{tabular}{|c|c|c|c|}
\hline \multicolumn{2}{|c|}{ Correspondance unique (mais sans réciprocité exclusive) } & \multicolumn{2}{|c|}{ Agroupement } \\
\hline & $>1$ espèce botanique, 1 genre & $>1$ genre, 1 famille & $>1$ famille \\
\hline 158 & 13 & 8 & 27 \\
\hline
\end{tabular}

Ces agroupements à différents niveaux taxonomiques se retrouvent également au niveau des séries à l'échelle d'un ou plusieurs informateurs (Tableau 3).

Tableau 3. Niveaux taxonomiques des agroupements d'espèces dans les séries (chaque numéro entre crochets renvoie à un identificateur différent). Agroupement : cas où un morphotype correspond à plusieurs espèces botaniques

\begin{tabular}{|l|l|}
\hline Niveaux taxonomiques des agroupements dans les séries & \multicolumn{1}{c|}{ Exemples } \\
\hline $\begin{array}{l}\text { Morphotypes regroupés dans une même série et appartenant } \\
\text { au même genre botanique }\end{array}$ & $\begin{array}{l}\text { abiuzeiro: } 8 \text { espèces de Pouteria (Sapotaceae) [1,3,5,6] } \\
\text { pitomba: 2 espèces d'Abuta (Menispermaceae) [1,3,4,5,6] } \\
\text { ingá: 9 espèces d'Inga (Fabaceae-Mimosoideae) [1,3,4,5,6] }\end{array}$ \\
\hline $\begin{array}{l}\text { Morphotypes regroupés dans une même série et de genres } \\
\text { botaniques (voire de familles) différents }\end{array}$ & $\begin{array}{l}\text { caniceiro: caniceiro branco (Lacistema sp. (esp 1), Lacistemaceae), caniceiro vermelho (Xylopia } \\
\text { sp. (esp.2). Annonaceae), caniceiro preto (Xylopia aromatica, Annonaceae) [4] } \\
\text { facheiro: facheiro branco (Rhabdodendron amazonicum, Rutaceae), facheiro preto (Swartzia } \\
\text { sp. (esp.1), Fabaceae-Papilionoideae) [1,3,5] } \\
\text { araçá: araçá branca (Myrcia sp. (esp.3), Myrtaceae), araçá vermelho (Eugenia sp., Myrtaceae) [1] }\end{array}$ \\
\hline
\end{tabular}

79 Les processus d'agroupements et de fragmentations s'opèrent à l'échelle de la taxonomie individuelle (taxonomie d'un même informateur, cas A et C du Tableau 4) ou dans la taxonomie populaire « commune ", impliquant l'ensemble des informateurs (cas B et D du Tableau 4). Dans ce dernier cas, l'agroupement, ou la fragmentation, pour un morphotype donné n'apparaît pas au niveau de la taxonomie individuelle mais seulement du fait de la juxtaposition des nomenclatures individuelles (ex dans le cas de l'agroupement du morão vermelho et dans le cas de la fragmentation du Rhabdodendron amazonicum (Rutaceae). Cette flexibilité de la nomenclature locale a d'ailleurs été clairement explicitée par les villageois eux-mêmes. 
Tableau 4. Agroupement et fragmentation des espèces botaniques dans la taxonomie individuelle (à l'échelle d'un informateur) ou "collective» (en prenant en compte l'ensemble des informateurs). Chaque numéro entre crochet renvoie à un identificateur différent.

\begin{tabular}{|c|c|c|}
\hline Cas de figure & & Exemples \\
\hline \multirow[t]{2}{*}{$\begin{array}{l}\text { Agroupement (un même nom populaire } \\
\text { attribué à plusieurs espèces) }\end{array}$} & $\begin{array}{c}\text { A l'échelle } \\
\text { d'un même informateur }\end{array}$ & $\begin{array}{l}\text { ingá da mata: } 3 \text { espèces différentes d'Inga sp. [5] } \\
\text { caniceiro: } 2 \text { espèces de Xylopia sp. [5] } \\
\text { abiu: } 2 \text { espèces de Pouteria sp. [5] } \\
\text { louro amarelo: } 2 \text { espèces de genres différents appartenant à la famille des } \\
\text { Lauraceae [5] } \\
\text { muirapixuna: Zygia latifolia (Fabaceae-Mimosoideae) et Ceasaria arborea } \\
\text { (Flacourtiaceae) [2] } \\
\text { Murteira: Myrcia fallax (Myrtaceae) et Xylopia sp. (esp 4, Annonaceae) [6] }\end{array}$ \\
\hline & $\begin{array}{c}\text { à l'échelle } \\
\text { de plusieurs informateurs }\end{array}$ & $\begin{array}{l}\text { ingáxixica: Inga heterophylla et Inga gracifolia }[3,4,6] \\
\text { ingá da mata: } 5 \text { espèces différentes d' Inga sp. }[1,3,5] \\
\text { morão vermelho: Eschweleira ovata (Lecythadaceae), Xylopia sp. et Xylopia } \\
\text { aromatica (Annonaceae), Couratari sp. (Lecythidaceae) [1,2,3,5,6] }\end{array}$ \\
\hline \multirow[b]{2}{*}{$\begin{array}{l}\text { Fragmentation (plusieurs noms populaires } \\
\text { attribués à une même espèce) }\end{array}$} & $\begin{array}{c}\text { A l'échelle } \\
\text { d'un même informateur }\end{array}$ & $\begin{array}{l}\text { Miconia sp. (esp 3) (Melastomataceae): lacre vermelho et Murteira [1] } \\
\text { Miconia sp (esp 2) (Melastomataceae): papateira branca et maramazeiro } \\
\text { vermelho [3] } \\
\text { Thyrsodium paraense (Anacardiaceae): uruazeiro [3], tenteiro vermelho [3] }\end{array}$ \\
\hline & $\begin{array}{c}\text { à l'échelle } \\
\text { de plusieurs informateurs }\end{array}$ & $\begin{array}{l}\text { Thyrsodium paraense (Anacardiaceae): uruazeiro [3], tenteiro [3], breu [3], pau } \\
\text { de tocandeira [1] } \\
\text { Miconia chrysophylla (Melastomataceae): maramarazeiro [3], lacre [1], caneleira } \\
{[4] \text {, papaterra }[2,6]} \\
\text { Croton cajucara (Euphorbiaceae): catituzeiro [1] et sacaca }[2,6] \\
\text { Siparuna guianensis (Monimiaceae): breurana [6], capitiü }[2,5] \text {, louro roxo [1] } \\
\text { Rhabdodendron amazonicum (Rutaceae): facheiro do branco [5], joão mole [3], } \\
\text { murapuama da branca [1], olho de cavalo [5] }\end{array}$ \\
\hline
\end{tabular}

\section{Conclusion}

Les relations qu'établissent les Ribeirinhos avec les végétaux se reflètent dans les catégories de plantes distinguées et leur nomenclature: ils font une opposition primordiale entre espèces domestiquées et espèces considérées sauvages, avec d'un côté le mato (adventices dans les abattis, espèces forestières sauvages non plantées) et de l'autre les plantas (espèces plantées) avec néanmoins une flexibilité entre ces deux catégories puisque certains matos peuvent être rattachés aux plantas s'ils bénéficient de soins particuliers de la part des agriculteurs. Les plantas sont donc en premier lieu catégorisées en fonction de la relation de proximité et d'attention que confère l'agriculteur au végétal.

81 À cette première catégorisation des végétaux se superposent d'autres catégories en fonction de caractéristiques essentiellement morphologiques des végétaux. Ces catégories sont également flexibles, un végétal pouvant se rattacher à plusieurs d'entre elles en fonction de ses caractéristiques propres, de son stade de croissance mais également des informateurs interrogés qui privilégieront une catégorie au détriment d'une autre pour un végétal donné.

De façon plus générale, la nomenclature locale renseigne sur différentes caractéristiques des végétaux, qu'elles soient liées à leur morphologie (taille, couleur, texture de l'écorce, fruits, graines, feuilles, exsudat...), à leur origine, leur utilisation locale ou leur écologie (distribution des espèces suivant le type de forêts ou de sols, types de parasites habitant dans la plante, consommateur primaire principal, agents disséminateurs des graines, caractéristique écologique liée au développement...). Cette nomenclature locale est riche mais également flexible. Elle reflète une hétérogénéité des connaissances de la part des informateurs vis-à-vis de la diversité végétale.

83 Enfin, cette étude, en mettant en parallèle les taxonomies populaire et scientifique, a mis en évidence une correspondance assez faible entre elles : d'une part, près de la moitié des morphotypes n'ont pas de correspondance unique et exclusive dans la taxonomie 
scientifique; d'autre part, un même morphotype regroupe fréquemment des espèces appartenant à des genres, voire à de familles différentes.

Je remercie l'UMR MNHN-IRD Patrimoines locaux, à laquelle j'étais rattachée durant cette étude, dans le cadre de ma thèse co-dirigée par Laure Emperaire

Je remercie le projet « Floresta em pé» du CIRAD.

Merci également au correcteur ou à la correctrice pour les remarques pertinentes qui ont aidé à améliorer ce papier.

\section{BIBLIOGRAPHIE}

Baraloto C., Ferreira E., Rockwell C. \& Walthier F. 2007 - Limitations and applications of parataxonomy for community forest management in Southwestern Amazonia. Ethnobotany Research and applications $5: 077-084$.

Couly C. 2009 - La biodiversité agricole et forestière des Ribeirinhos de la Forêt Nationale du Tapajós (Pará, Brésil) : usages, gestion et savoirs. Thèse de doctorat en ethnobiologie, cotutelle Muséum nationale d'Histoire naturelle - Université de Brasília, Paris, 325 p + Annexes [En ligne] http:// hal.archives-ouvertes.fr/tel-00597906/

Couly C. \& Sist P. 2012 - Use and knowledge of forest plants among the Ribeirinhos, a traditional Amazonian population. Agroforestry system 87 (3) : 517-523.

Denevan W. \& Padoch C. 1988 - Swidden-fallow agroforestry in the Peruvian Amazon. Advances in Economic Botany (5), 107 p.

Friedberg C. 1986 - Classifications populaires des plantes et modes de connaissances. In : Tassy P. (Ed.), L'Ordre et la diversité du vivant. Quel statut scientifique pour les classifications biologiques? Paris, Fondation Diderot, Fayard : 22-49.

Friedberg C. 1990 - Le savoir botanique des Bunaq : percevoir et classer dans le Haut Lamaknen (Timor, Indonésie). Mémoire du Muséum national d'Histoire naturelle, Botanique 32, 289 p.

Lawrence D.C. \& Mogea J.P. 1996 - A preliminary analysis of tree diversity in the landscape under shifting cultivation north of gunung palung national park. Tropical biodiversity 3 (3) : 297-319.

Padoch C. \& De Jong W. 1992 - Diversity, variation and change in Ribeiriños agriculture. In Redfort K.H. \& Padoch C. (Ed.), Conservation of neotropical forests. Working from traditional resources uses. New York, Columbia University Press, $457 \mathrm{p}$.

Phillips O., Gentry A.H., Reynel C., Wilkin P. \& Galves-Durand C.B. 1994 - Quantitative ethnobotany and Amazonian conservation. Conservation Biology 8 : 225-48.

Wilkie P. \& Saridan A. 1999 - The limitations of vernacular names in an inventory study, Central Kalimatan, Indonesia. Biodiversity and Conservation 8 : 1457-1467. 


\section{ANNEXES}

Liste des morphotypes cultivés et forestiers (jardins, abattis, forêts) connus par les Ribeirinhos de la Flona Tapajós, avec leur correspondance dans la nomenclature scientifique.

\section{Abacateiro - Apui}

\begin{tabular}{|c|c|c|c|c|c|c|}
\hline Noms vernaculaires & Noms scientifiques & Familles & Jd & $A b$ & FdT & Ig \\
\hline Abacateiro & Persea americana Mill. & Lauraceae & * & * & & \\
\hline Abacatirana & Non identifié & Lauraceae & & & * & \\
\hline Abacaxi & Ananas comosus $\mathrm{L}$. & Bromeliaceae & * & * & & \\
\hline Abiu & $\begin{array}{l}\text { Pouteria sp. (esp 1) } \\
\text { Pouteria sp. (esp 6) }\end{array}$ & Sapotaceae & & & * & \\
\hline Abiu branco & Non identifié & Sapotaceae & & & * & \\
\hline Abiu cabeza de macaco & Non identifié & Sapotaceae & & & * & \\
\hline Abiu cutite & Non identifié & Sapotaceae & & & * & \\
\hline Abiu felpudo/cabeludo & $\begin{array}{l}\text { Pouteria sp. (esp 5) } \\
\text { Pouteria sp. (esp 7) }\end{array}$ & Sapotaceae & & & * & \\
\hline Abiu liso/ cascaduro & $\begin{array}{l}\text { Pouteria sp. (esp 2) } \\
\text { Pouteria sp. (esp 6) } \\
\text { Pouteria sp. (esp 8) }\end{array}$ & Sapotaceae & & & * & \\
\hline Abiu vermelho & Pouteria sp. (esp 4) & Sapotaceae & & & * & \\
\hline Abiurana & Pouteria sp. (esp 3) & Sapotaceae & & & * & \\
\hline Abuta & Abuta cf. panhi & Menispermaceae & & & * & \\
\hline Açai & Euterpe oleracea Mart. & Arecaceae & * & & & * \\
\hline Acariquara & Minquartia guianensis Aubl. & Olacaceae & & & * & \\
\hline Acerola & Malpighia glabra L. & Malpighiaceae & * & & & \\
\hline Afacava brava & $\begin{array}{l}\text { Spathelia excelsa Krause (Coxam \& } \\
\text { Brizicky) }\end{array}$ & Rutaceae & & & * & \\
\hline Amapá & Brosimum sp. & Moraceae & & * & * & \\
\hline Amarelão & Non identifié & Non identifiée & & & ${ }^{*}$ & \\
\hline Ameiju & Non identifié & Non identifiée & & & * & \\
\hline Andiroba & Carapa guianensis Aubl. & Meliaceae & * & * & * & \\
\hline Angelim brinco de princessa & Non identifié & Fabaceae & & & * & \\
\hline Angelim da branca & Non identifié & Fabaceae & & & * & \\
\hline Angelim pedra/ vermelha & Dinizia excelsa Ducke & Fabaceae-mimosoïdeae & & & * & \\
\hline Aninga da mata & Non identifié & Non identifiée & & & * & \\
\hline Apuí & Ficus sp. & Moraceae & & & * & \\
\hline
\end{tabular}




\section{Aquiquizeiro - Batata}

\begin{tabular}{|c|c|c|c|c|c|c|}
\hline Noms vernaculaires & Noms scientifiques & Familles & Jd & $A b$ & FdT & $\lg$ \\
\hline Aquiquizeiro & Non identifié & Non identifiée & & & * & \\
\hline Araçá castanha & Non identifié & Myrtaceae & & & * & \\
\hline $\begin{array}{l}\text { Araçá da mata/ } \\
\text { Araçá de jaboti/ } \\
\text { Araçá pixuna }\end{array}$ & $\begin{array}{l}\text { Eugenia sp. (esp 1) } \\
\text { Myrcia sp. (esp 1) } \\
\text { Myrcia sp. (esp 2) } \\
\text { Myrcia sp. (esp 5) }\end{array}$ & Myrtaceae & & & * & \\
\hline Araçá da praia/quintal & Non identifié & Myrtaceae & * & & & \\
\hline Araçá pixuna branco & $\begin{array}{l}\text { Myrcia sp. (esp 3) } \\
\text { Myrcia sp. (esp 4) }\end{array}$ & Myrtaceae & & & * & \\
\hline Araçá pixuna vermelho & $\begin{array}{l}\text { Eugenia sp. } \\
\text { Myrcia sp. (esp 6) }\end{array}$ & Myrtaceae & & & * & \\
\hline Araça preta & Non identifié & Myrtaceae & & & * & \\
\hline Araparizeiro & Manolobium sp. & $\begin{array}{l}\text { Fabaceae- } \\
\text { Papilionoideae }\end{array}$ & & & * & * \\
\hline Arumã & Ischnosiphon sp. (esp 1) & Marantaceae & & & * & \\
\hline Assarinheira branca & Non identifié & Non identifiée & & & * & \\
\hline Ata da mata & $\begin{array}{l}\text { Croton sp. } \\
\text { Duquetia sp (esp 1) }\end{array}$ & $\begin{array}{l}\text { Euphorbiaceae } \\
\text { Annonaceae }\end{array}$ & & & * & \\
\hline Ata do quintal & Croton sp. & Euphorbiaceae & * & & & \\
\hline Atarana da mata & Guatteria sp. (esp 2) & Annonaceae & & & * & \\
\hline Axuá da beira & Non identifié & Humiriaceae & & & * & \\
\hline $\begin{array}{l}\text { Axuá da mata/Axua do } \\
\text { morcego }\end{array}$ & Non identifié & Humiriaceae & & & * & \\
\hline Babaçu & Attalea speciosa Mart. ex Spreng. & Arecaceae & & & * & \\
\hline Bacabeira & $\begin{array}{l}\text { Oenocarpus bacaba Mart. } \\
\text { Oenocarpus distichus Mart. }\end{array}$ & Arecaceae & * & * & * & \\
\hline Bacuri & $\begin{array}{l}\text { Platonia insignis Mart. } \\
\text { Rheedia macrophylla (Mart.) Planch \& } \\
\text { Triana }\end{array}$ & Clusiaceae & & & * & \\
\hline Bambu & Non identifié & Poaceae-Bambusoideae & * & & & \\
\hline Bananeira & Musa sp. & Musaceae & & ${ }^{*}$ & & \\
\hline Bananinha & Tabernaemontana angulata Müll. Arg. & Apocynaceae & & & * & \\
\hline Batata & Ipomoea batata (L.) Lam. & Convolvulaceae & & * & & \\
\hline
\end{tabular}

\section{Boa macaca - Caneleira de velha preta}

\begin{tabular}{|c|c|c|c|c|c|c|}
\hline Noms vernaculaires & Noms scientifiques & Familles & Jd & $A b$ & FdT & $\lg$ \\
\hline Boa macaca & Non identifié & Humiriaceae & & & * & \\
\hline Breu mescla & Non identifié & Burseraceae & & & * & \\
\hline Breu branco & Protium sp. (esp 1) & Burseraceae & & & * & \\
\hline Breu manga & Non identifié & Burseraceae & & & * & \\
\hline Breu pequeno & Protium sp. (esp 1) & Burseraceae & & & * & \\
\hline Breu sucuruba & Trattinnickia rhoifolia Willd. & Burseraceae & & & * & \\
\hline Breu vermelho & Thyrsodium paraense Huber & Anacardiaceae & & & * & \\
\hline Breurana & Siparuna guianensis Aubl. & Monimiaceae & & & * & \\
\hline Breu grande & Non identifié & Burseraceae & & & * & \\
\hline Broqueira & Non identifié & Non identifiée & & & * & \\
\hline Buriti & Mauritia flexuosa L. f. & Arecaceae & & & & * \\
\hline Cacau da mata & Theobroma sp. (esp 1) & Sterculiaceae & & * & * & \\
\hline Cacau do quintal & Theobroma sp. & Sterculiaceae & * & * & & \\
\hline Café & Coffea arabica L. & Rubiaceae & * & & & \\
\hline Caferana & Non identifié & Rubiaceae & & & * & \\
\hline Cajussara & Solanum sp. & Solanaceae & & & * & \\
\hline Cajuarana & Simaba sp. & Simaroubaceae & & & & * \\
\hline Cajueiro & Anacardium occidentale L. & Anacardiaceae & ${ }^{\star}$ & * & & \\
\hline Camucamu & Chrysobalanus sp. & Chrysobalanaceae & ${ }^{\star}$ & & & \\
\hline Cana & Saccharum officinarum $\mathrm{L}$. & Poaceae & & * & & \\
\hline Canamança da mata & Non identifié & Non identifiée & & & * & \\
\hline $\begin{array}{l}\text { Caneleira de velha } \\
\text { vermelha }\end{array}$ & $\begin{array}{l}\text { Casearia javitensis H.B.K } \\
\text { Tapirira guianensis Aubl. } \\
\text { Non identifié }\end{array}$ & $\begin{array}{l}\text { Flacourtiaceae } \\
\text { Anacardiaceae } \\
\text { Flacourtiaceae }\end{array}$ & & & * & \\
\hline $\begin{array}{l}\text { Caneleira de velha amarela } \\
\text { (branca) }\end{array}$ & $\begin{array}{l}\text { Miconia sp. (esp 1) } \\
\text { Casearia javitensis H.B.K } \\
\text { Miconia chrysophylla (Rich.) Urb. } \\
\text { Non identifié }\end{array}$ & $\begin{array}{l}\text { Melastomataceae } \\
\text { Flacourtiaceae } \\
\text { Melastomataceae } \\
\text { Fabaceae }\end{array}$ & & & * & \\
\hline Caneleira de velha preta & Casearia javitensis H.B.K & Flacourtiaceae & & & * & \\
\hline
\end{tabular}




\section{Caniceiro - Cedro}

\begin{tabular}{|c|c|c|c|c|c|c|}
\hline Noms vernaculaires & Noms scientifiques & Familles & Jd & $A b$ & FdT & $\lg$ \\
\hline Caniceiro & $\begin{array}{l}\text { Xylopia sp. (esp 2) } \\
\text { Xylopia sp. (esp 3) } \\
\text { Xylopia sp. (esp1) }\end{array}$ & Annonaceae & & & * & \\
\hline Caniceiro branco & $\begin{array}{l}\text { Lacistema sp. (esp 1) } \\
\text { Xylopia sp. (esp 5) }\end{array}$ & $\begin{array}{l}\text { Lacistemataceae } \\
\text { Annonaceae }\end{array}$ & & & * & \\
\hline Caniceiro preto & Xylopia aromatica (Lam.) Mart. & Annonaceae & & & * & \\
\hline Caniceiro vermelho & Xylopia sp. (esp 2) & Annonaceae & & & * & \\
\hline Capim amargo & Non identifié & Poaceae & * & * & & \\
\hline Capim cidreira & Non identifié & Poaceae & * & & & \\
\hline Capim barba de bode & Non identifié & Poaceae & * & * & & \\
\hline Capim pacuã & Non identifié & Poaceae & * & * & & \\
\hline Capim pinda & Non identifié & Poaceae & * & * & & \\
\hline Capim santo & Non identifié & Poaceae & * & & & \\
\hline Capitiú & Siparuna guianensis Aubl. & Monimiaceae & & & ${ }^{*}$ & \\
\hline Cará & Non identifié & Dioscoreaceae & & ${ }^{*}$ & & \\
\hline Caracaxa & Non identifié & Non identifiée & & & * & \\
\hline Caraipé branco & Licania sp. & Chrysobalanaceae & & & $\stackrel{*}{*}$ & \\
\hline Caraipé vermelho & Licania sp. & Chrysobalanaceae & & & * & \\
\hline Carambola & Averrhoa carambola L. & Oxalidaceae & * & & & \\
\hline Carapanaúba & Aspidosperma sp. & Apocynaceae & & & * & \\
\hline Carmelitana & Non identifié & Poaceae & * & & & \\
\hline Caruareira & Helicostylis tomentosa (Poepp et Endl.) & Moraceae & & & ${ }^{*}$ & \\
\hline Casca preciosa & Non identifié & Lauraceae & & & ${ }^{*}$ & \\
\hline Castanha sapucaia & Lecythis pisonis Cambess. & Lecythidaceae & & & ${ }^{\star}$ & \\
\hline Castanha de arara & Tabebuia sp. & Bignoniaceae & & & ${ }^{*}$ & \\
\hline Castanha do Pará & Bertholletia excelsa H.B.K & Lecythidaceae & & * & ${ }^{*}$ & \\
\hline Catituzeiro & $\begin{array}{l}\text { Licania sp. (esp 1) } \\
\text { Croton cajucara Benth. }\end{array}$ & $\begin{array}{l}\text { Chrysobalanaceae } \\
\text { Euphorbiaceae }\end{array}$ & & & * & \\
\hline Caxirica & Ischnosiphon sp. & Marantaceae & & & * & \\
\hline Cedro & Cedrela odorata L. & Meliaceae & * & * & * & \\
\hline
\end{tabular}

Cedro-Mogno - Cipó tingá

\begin{tabular}{|c|c|c|c|c|c|c|}
\hline Noms vernaculaires & Noms scientifiques & Familles & Jd & $A b$ & FdT & Ig \\
\hline Cedro-mogno & Non identifié & Meliaceae & & & * & \\
\hline Cipó alho & Mansoa aliaceae Gentry & Bignoniaceae & * & * & * & \\
\hline Cipó cororó timbo & Non identifié & Araceae & & & * & \\
\hline Cipó ambé & $\begin{array}{l}\text { Philodendron spruceanum (Schott) } \\
\text { G.M. Barroso }\end{array}$ & Araceae & & & * & \\
\hline Cipo cruzeiro branca & Non identifié & Araceae & & & * & \\
\hline Cipó da água & Non identifié & Araceae & & & * & \\
\hline Cipó matarana & Non identifié & Araceae & & & * & \\
\hline Cipó da mata & Non identifié & Araceae & & & * & \\
\hline Cipó mucunã & Non identifié & Non identifiée & & & * & \\
\hline Cipó de fogo & $\begin{array}{l}\text { Danila sp. } \\
\text { Memora sp. }\end{array}$ & $\begin{array}{l}\text { Dillenaceae } \\
\text { Bignoniaceae }\end{array}$ & & & * & \\
\hline Cipó escada de jaboti & Bauhinia guianensis Aubl. & $\begin{array}{l}\text { Fabaceae- } \\
\text { Caesalpinioideae }\end{array}$ & & & * & \\
\hline Cipó gapuí & Abuta sp. (esp 2) & Menispermaceae & & & * & \\
\hline Cipó jabuti muta & Non identifié & Non identifiée & & & * & \\
\hline Cipó liso branco & $\begin{array}{l}\text { Non identifié } \\
\text { Memora flavida (A.P. De Candolle) } \\
\text { Bureau et K. Schumann }\end{array}$ & $\begin{array}{l}\text { Fabaceae } \\
\text { Bignoniaceae }\end{array}$ & & & * & \\
\hline Cipó liso de vermelho & Non identifié & Non identifiée & & & * & \\
\hline Cipó macaco de coinha & Non identifié & Non identifiée & & & * & \\
\hline Cipó macaco=macaco cipó & Non identifié & Non identifiée & & & * & \\
\hline Cipó preto & Non identifié & Non identifiée & & & * & \\
\hline Cipó quina & Non identifié & Non identifiée & & & * & \\
\hline Cipó rabo de camaleão & $\begin{array}{l}\text { Mimosa sp. (esp 1) } \\
\text { Mimosa sp. (esp 2) }\end{array}$ & Fabaceae-Mimosoideae & & & * & \\
\hline Cipó taia & Non identifié & Non identifiée & & & * & \\
\hline Cipó taracuá & Non identifié & Araceae & & & ${ }^{*}$ & \\
\hline Cipó timborana & Lonchocarpus floribundus Benth. & $\begin{array}{l}\text { Fabaceae- } \\
\text { Papilionoideae }\end{array}$ & & & * & \\
\hline Cipó tingá & Heteropsis sp. Kunth & Araceae & & & * & \\
\hline
\end{tabular}


Cipó titica - Embaúba picuda

\begin{tabular}{|c|c|c|c|c|c|c|}
\hline Noms vernaculaires & Noms scientifiques & Familles & Jd & $A b$ & FdT & $\lg$ \\
\hline Cipó titica & Heteropsis flexuosa Kunth & Araceae & & & * & \\
\hline Cipó traira & Non identifié & Non identifiée & & & * & \\
\hline Cipó xafari & Non identifié & Non identifiée & & & * & \\
\hline Copaiba & Copaifera martii Hayne & $\begin{array}{l}\text { Fabacea- } \\
\text { caesalpinideae }\end{array}$ & * & * & * & \\
\hline Copaibarana do vermelho & Copaifera sp. & $\begin{array}{l}\text { Fabaceae- } \\
\text { Caesalpinioideae }\end{array}$ & & & * & \\
\hline Coqueiro & Cocos nucifera & Arecaceae & * & & & \\
\hline Corticeira & $\begin{array}{l}\text { Stryphnodendron pulcherrimum (Willd) } \\
\text { Hochr. }\end{array}$ & Fabaceae-Mimosoideae & & & * & \\
\hline Cravinio & Non identifié & Non identifiée & & & * & \\
\hline Cuiarana & Terminalia sp. (esp 2) & Combretaceae & & & * & \\
\hline Cumai & Parahancornia amapa (Huber) Ducke & Apocynaceae & & & * & \\
\hline Cumandá & Campsiandra laurifolia Benth. & $\begin{array}{l}\text { Fabaceae- } \\
\text { Caesalpinioideae }\end{array}$ & & & * & * \\
\hline Cumaru branco & Dipteryx odorata (Aubl.) Willd & $\begin{array}{l}\text { Fabaceae- } \\
\text { Papilionoideae }\end{array}$ & & & * & \\
\hline Cumaru grande & Dipteryx odorata (Aubl.) Willd & $\begin{array}{l}\text { Fabaceae- } \\
\text { Papilionoideae }\end{array}$ & & * & * & \\
\hline Cumaru preto & Ormosia sp. & $\begin{array}{l}\text { Fabaceae- } \\
\text { Papilionoideae }\end{array}$ & & & * & \\
\hline Cumaru vermelho & Dipteryx sp. & $\begin{array}{l}\text { Fabaceae- } \\
\text { Papilionoideae }\end{array}$ & & & * & \\
\hline Cumaruí & Non identifié & Non identifiée & & & * & \\
\hline Cupuaçú & $\begin{array}{l}\text { Theobroma grandiflorum (Willd. ex } \\
\text { Spreng.) K. Schum }\end{array}$ & Sterculiaceae & * & * & * & \\
\hline Curuá & $\begin{array}{l}\text { Attalea attaleoides (Barb. Rodr.) Wess. } \\
\text { Boer. }\end{array}$ & Arecaceae & & & * & \\
\hline Curumim & Non identifié & Non identifiée & & & * & \\
\hline Embaúba branca & Cecropia palmata Willd. & Cecropiaceae & & & * & \\
\hline Embaúba da capoeira & Cecropia palmata Willd. & Cecropiaceae & & & * & \\
\hline Embaúba de veado & Cecropia sp. (esp 2) & Cecropiaceae & & & * & \\
\hline Embaúba picuda & Cecropia sp. (esp 3) & Cecropiaceae & & & * & \\
\hline
\end{tabular}

Embaúba vermelha - Goiaba de anta

\begin{tabular}{|c|c|c|c|c|c|c|}
\hline Noms vernaculaires & Noms scientifiques & Familles & Jd & $A b$ & FdT & $\lg$ \\
\hline Embaúba vermelha & Cecropia palmata Willd. & Cecropiaceae & & & * & \\
\hline Envira branca & $\begin{array}{l}\text { Cochlospermum orinoccense (H.B.K) St } \\
\text { end. } \\
\text { Rollinia sp. }\end{array}$ & $\begin{array}{l}\text { Cochlospermaceae } \\
\text { Annonaceae } \\
\text { Annonaceae }\end{array}$ & & & * & \\
\hline Envira preta & $\begin{array}{l}\text { Guatteria sp. (esp 1) } \\
\text { Guatteria melosma Diels. } \\
\text { Rollinia sp. }\end{array}$ & Annonaceae & & & * & \\
\hline Envira-taia & Non identifié & Non identifiée & & & * & \\
\hline Envirola vermelha & Virola sp. & Myristicaceae & & & * & \\
\hline Envirola branca & Virola sp. & Myristicaceae & & & * & \\
\hline Erva de passarinho & Pitirusa sp. & Loranthaceae & & & * & \\
\hline Facheiro & $\begin{array}{l}\text { Swartzia sp. (esp 1) } \\
\text { Xylopia benthami R.E.Fr. }\end{array}$ & $\begin{array}{l}\text { Fabaceae- } \\
\text { Papilionoideae, } \\
\text { Annonaceae }\end{array}$ & & & * & \\
\hline $\begin{array}{l}\text { Facheiro (=kikizeiro) } \\
\text { vermelho }\end{array}$ & Non identifié & Non identifiée & & & * & \\
\hline Facheiro do branco & $\begin{array}{l}\text { Rhabdodendron amazonicum (Spruce } \\
\text { ex. Benth.) Huber } \\
\text { Sloanea sp. }\end{array}$ & $\begin{array}{l}\text { Rutaceae } \\
\text { Eleocarpaceae }\end{array}$ & & & * & \\
\hline Facheiro do preto & Swartzia sp. (esp 1) & $\begin{array}{l}\text { Fabaceae- } \\
\text { Papilionoideae }\end{array}$ & & & * & \\
\hline Fava da mata amarga & Vatairea paraensis Ducke & $\begin{array}{l}\text { Fabaceae- } \\
\text { Papilionoideae }\end{array}$ & & & * & \\
\hline $\begin{array}{l}\text { Fava da mata branca= } \\
\text { Caracaxazeiro }\end{array}$ & Non identifié & Fabaceae & & & * & \\
\hline Fava da mata vermelha & Non identifié & Fabaceae & & & * & \\
\hline Feijão (3 variétés) & Phaseolus vulgaris $\mathrm{L}$. & $\begin{array}{l}\text { Fabaceae- } \\
\text { Papilionoideae }\end{array}$ & & * & & \\
\hline Ferrão de arraia & Non identifié & Non identifiée & & & * & \\
\hline Ginja da mata & Lindackeria paraensis Kuhlm & Flacourtiaceae & & & * & \\
\hline Ginja da quintal & Non identifié & Flacourtiaceae & & & & \\
\hline Ginja do quintal & Eugenia patrisii Vahl & Myrtaceae & * & & & \\
\hline Goiaba & Psidium guajava L. & Myrtaceae & * & * & & \\
\hline Goiaba de anta & Bellucia sp. & Melastomataceae & & & * & \\
\hline
\end{tabular}


Goiabarana da mata - Jaca

\begin{tabular}{|c|c|c|c|c|c|c|}
\hline Noms vernaculaires & Noms scientifiques & Familles & Jd & $A b$ & FdT & $\lg$ \\
\hline Goiabarana da mata & Non identifié & Myrtaceae & & & * & \\
\hline Graviola & Annona muricata $\mathrm{L}$. & Annonaceae & & * & & \\
\hline Guariúba amarelo & Clarisia racemosa Ruiz \& Pav. & Moraceae & & & * & \\
\hline Guariúba preto & Non identifié & Non identifiée & & & * & \\
\hline Gumbera da mata & Non identifié & Non identifiée & & & * & \\
\hline Hortelã & Mentha sp. L. & Lamiaceae & * & & & \\
\hline Inajá & Maximiliana maripa (Aubl.) Drude & Arecaceae & & & * & \\
\hline Ingá branco & Inga sp. & Fabaceae-Mimosoideae & & & * & \\
\hline Ingá cabeludo & Inga sp. (esp 1) & Fabaceae-Mimosoideae & & & * & \\
\hline Ingá comum & Inga sp. & Fabaceae-Mimosoideae & & * & * & \\
\hline Ingá corda (planta)/Ingá cipó & Inga edulis Mart. & Fabaceae-Mimosoideae & * & & & \\
\hline Ingá da beira & Inga sp. & Fabaceae-Mimosoideae & & & & * \\
\hline Ingá da mata (=Ingarana) & $\begin{array}{l}\text { Inga sp. (esp 3) } \\
\text { Inga sp. (esp 4) } \\
\text { Inga sp. (esp 5) } \\
\text { Inga sp. (esp 6) } \\
\text { Inga alba (Sw.) Willd. }\end{array}$ & Fabaceae-Mimosoideae & & & * & \\
\hline Ingá do macaco & Inga sp. (esp 2) & Fabaceae-Mimosoideae & & & * & \\
\hline Ingá vermelho & Non identifié & Fabaceae-Mimosoideae & & & * & \\
\hline Ingáxixica & $\begin{array}{l}\text { Inga heterophylla Willd. } \\
\text { Inga gracilifolia Ducke }\end{array}$ & Fabaceae-Mimosoideae & & & * & \\
\hline Inga grande & Inga sp. (esp 2) & Fabaceae-Mimosoideae & & & * & \\
\hline Itaúba & $\begin{array}{l}\text { Mezilauros itauba (Meisn.) Taub. ex } \\
\text { Mez }\end{array}$ & Lauraceae & & * & * & \\
\hline Itaúba abacate & Non identifié & Lauraceae & & & * & \\
\hline Itaúba amarela (ou branca) & Non identifié & Lauraceae & & & * & \\
\hline Itaúba preta//taúba da praia & Pouteria sp. & Sapotaceae & & & * & \\
\hline Itaúba vermelho & Non identifié & Lauraceae & & & * & \\
\hline Itaúbarana & Terminalia sp. (esp 1) & Combretaceae & & & * & \\
\hline Jaca & Artocarpus heterophylla Lam. & Moraceae & * & & & \\
\hline
\end{tabular}

\section{Jacarandá - Jutaí miudinho}

\begin{tabular}{|c|c|c|c|c|c|c|}
\hline Noms vernaculaires & Noms scientifiques & Familles & Jd & $\mathbf{A b}$ & FdT & Ig \\
\hline Jacarandá & $\begin{array}{l}\text { Dalbergia sp. } \\
\text { Maprounea guianensis Aubl. }\end{array}$ & $\begin{array}{l}\text { Fabaceae } \\
\text { Euphorbiaceae }\end{array}$ & & & * & \\
\hline Jacitara & $\begin{array}{l}\text { Desmoncus polyacanthus Mart. } \\
\text { Desmoncus orthocanhos Mart. }\end{array}$ & Arecaceae & & & * & \\
\hline Janitá & Brosium sp. (esp 2) & Moraceae & & & * & \\
\hline Janitá branca & Non identifié & Moraceae & & & * & \\
\hline Janitá vermelha & $\begin{array}{l}\text { Swartzia sp. (esp 3) } \\
\text { Brosium sp. (esp 2) } \\
\text { Swartzia sp. (esp 4) }\end{array}$ & $\begin{array}{l}\text { Fabaceae- } \\
\text { Papilionoideae } \\
\text { Moraceae } \\
\text { Fabaceae- } \\
\text { Papilionoideae }\end{array}$ & & & * & \\
\hline João mole & $\begin{array}{l}\text { Neea oppositifolia Ruiz \& Pav. } \\
\text { Rhabdodendron amazonicum (Spruce } \\
\text { ex. Benth.) Huber } \\
\text { Neea floribunda Poepp. \&Endl. }\end{array}$ & $\begin{array}{l}\text { Nyctaginaceae } \\
\text { Rutaceae } \\
\text { Nyctaginaceae }\end{array}$ & & & * & \\
\hline João mole branco & Miconia sp. (esp 3) & Melastomataceae & & & * & \\
\hline João mole vermelho & $\begin{array}{l}\text { Croton sp. } \\
\text { Pouteria sp. (esp 6) }\end{array}$ & $\begin{array}{l}\text { Euphorbiaceae } \\
\text { Sapotaceae }\end{array}$ & & & * & \\
\hline Japecanga & Non identifié & Non identifiée & & & * & \\
\hline Jará & Non identifié & Sapotaceae & & & & $*$ \\
\hline Jarana & Lecythis lurida (Miers) Mori & Lecythidaceae & & & * & \\
\hline Jarana vermelho & Clarisia sp. & Moraceae & & & * & \\
\hline Jatobá da mata & Hymenaea courbaril L. & $\begin{array}{l}\text { Fabaceae- } \\
\text { Caesalpinioideae }\end{array}$ & & & * & \\
\hline Jauari & Bactris sp. (esp 3) & Arecaceae & & & & * \\
\hline Jenipapo do iguapó & Non identifié & Rubiaceae & & & & * \\
\hline Jerimum & Cucurbita pepo L. & Cucurbitaceae & & * & & \\
\hline Jucá & Caesalpinia ferrea Mart. ex. Tul. & $\begin{array}{l}\text { Fabaceae- } \\
\text { Caesalpinioideae }\end{array}$ & $*$ & & & \\
\hline Juquiri & Non identifié & Non identifiée & & & * & \\
\hline Jurubeba & Solanum sp. & Solanaceae & & & * & \\
\hline Jutai miudinho & Hymenaea sp. & $\begin{array}{l}\text { Fabaceae- } \\
\text { Caesalpinioideae }\end{array}$ & & & * & \\
\hline
\end{tabular}


Jutaí-jatobá - Louro preto

\begin{tabular}{|c|c|c|c|c|c|c|}
\hline Noms vernaculaires & Noms scientifiques & Familles & Jd & $A b$ & FdT & $\lg$ \\
\hline Jutai-jatobá & Hymenaea sp. & $\begin{array}{l}\text { Fabaceae- } \\
\text { Caesalpinioideae }\end{array}$ & & & * & \\
\hline Jutai-jatobá da praia & Hymenaea sp. & $\begin{array}{l}\text { Fabaceae- } \\
\text { Caesalpinioideae }\end{array}$ & & & & * \\
\hline Jutai-mirim & Hymenaea sp. & $\begin{array}{l}\text { Fabaceae- } \\
\text { Caesalpinioideae }\end{array}$ & & & * & \\
\hline Jutai-peuá & Hymenaea sp. & $\begin{array}{l}\text { Fabaceae- } \\
\text { Caesalpinioideae }\end{array}$ & & & * & \\
\hline Jutai-pororoca (ou Pororoca) & Hymenaea parvifolia Hüber & $\begin{array}{l}\text { Fabaceae- } \\
\text { Caesalpinioideae }\end{array}$ & & & * & \\
\hline Jutaí & Hymenaea parvifolia Hüber & $\begin{array}{l}\text { Fabaceae- } \\
\text { Caesalpinioideae }\end{array}$ & & & * & \\
\hline Lacre branco & $\begin{array}{l}\text { Vismia cayannensis (Jacq.) Pers } \\
\text { Vismia guianensis Pers. }\end{array}$ & Clusiaceae & & * & * & \\
\hline Lacre vermelho & $\begin{array}{l}\text { Vismia cayannensis (Jacq.) Pers } \\
\text { Miconia chrysophylla (Rich.) Urb. } \\
\text { Miconia sp. (esp 3) } \\
\text { Vismia guianensis Pers. }\end{array}$ & $\begin{array}{l}\text { Clusiaceae } \\
\text { Melastomataceae } \\
\text { Clusiaceae }\end{array}$ & & * & * & \\
\hline Laranjeira & Citrus sp. & Rutaceae & * & * & & \\
\hline Limão & Citrus sp. & Rutaceae & & * & & \\
\hline Lingua de vaca & Heliconia sp. & Heliconiaceae & & & * & \\
\hline Louro amarelo & Ocotea sp. (esp 2) & Lauraceae & & & * & \\
\hline Louro bosta & Non identifié & Lauraceae & & & * & \\
\hline Louro branco & Ocotea sp. & Lauraceae & & & * & \\
\hline Louro cânfora & Non identifié & Lauraceae & & & * & \\
\hline $\begin{array}{l}\text { Louro da folha graúda } \\
\text { (Louro cascudo=Louro da } \\
\text { casca grossa) }\end{array}$ & Ocotea sp. (esp 1) & Lauraceae & & & * & \\
\hline Louro Itaúba & Non identifié & Lauraceae & & & * & \\
\hline $\begin{array}{l}\text { Louro miúdo = Loura da } \\
\text { folha miudinha= Louro da } \\
\text { casca miúda }\end{array}$ & Non identifié & Lauraceae & & & * & \\
\hline Louro pedra & Non identifié & Lauraceae & & & * & \\
\hline $\begin{array}{l}\text { Louro preto (Louro da casca } \\
\text { curucuru) }\end{array}$ & $\begin{array}{l}\text { Nectandra cuspidata Nees \& Mart. } \\
\text { Ocotea sp. }\end{array}$ & $\begin{array}{l}\text { Lauraceae } \\
\text { Lauraceae }\end{array}$ & & & * & \\
\hline
\end{tabular}

\section{Louro rosa - Mastruz}

\begin{tabular}{|c|c|c|c|c|c|c|}
\hline Noms vernaculaires & Noms scientifiques & Familles & Jd & $A b$ & FdT & Ig \\
\hline Louro rosa & Non identifié & Lauraceae & & & * & \\
\hline Louro roxo & $\begin{array}{l}\text { Siparuna guianensis Aubl. } \\
\text { Non identifié }\end{array}$ & $\begin{array}{l}\text { Monimiaceae } \\
\text { Lauraceae }\end{array}$ & & & * & \\
\hline Louro vermelho & Nectandra sp. (esp 1) & Lauraceae & & & * & \\
\hline Louro chumbo & Non identifié & Lauraceae & & & * & \\
\hline Macaqueiro & Eschweilera sp. (esp 2) & Lecythidaceae & & & * & \\
\hline Maçaranduba & Manilkara huberi (Ducke) Chevalier & Sapotaceae & & & * & \\
\hline $\begin{array}{l}\text { Macaxeira (manioc doux, } 4 \\
\text { variétés) }\end{array}$ & Manihot esculenta Crantz. & Euphorbiaceae & & * & & \\
\hline Mamoeiro & Carica papaya $L$. & Caricaceae & * & & & \\
\hline Mangaba & $\begin{array}{l}\text { Casearia sp. (esp 2) } \\
\text { Cassia lucens Vogel }\end{array}$ & $\begin{array}{l}\text { Flacourtiaceae } \\
\text { Fabaceae- } \\
\text { Caesalpinioideae }\end{array}$ & & & * & \\
\hline Mangueira & Mangifera indica $\mathrm{L}$. & Anacardiaceae & * & & & \\
\hline $\begin{array}{l}\text { Maniva (manioc amer) (25 } \\
\text { variétés) }\end{array}$ & Manihot esculenta Crantz. & Euphorbiaceae & & * & & \\
\hline Maparajuba & Manilkara paraensis (Huber) Standl. & Sapotaceae & & & * & \\
\hline Maracujá & Passiffora maliformis $\mathrm{L}$. & Passifloraceae & * & & & \\
\hline Maracatiara & Genre indeterminé & Non identifiée & & & * & \\
\hline Maracujá do rato & Passiflora sp. & Passifloraceae & & & $*$ & \\
\hline Marai & Bactris sp. (esp 3) & Arecaceae & & & $*$ & \\
\hline Maramarazeiro da branca & Miconia chrysophylla (Rich.) Urb. & Melastomataceae & & & * & \\
\hline Maramazeiro vermelho & Miconia sp. (esp 2) & Melastomataceae & & & * & \\
\hline Marapuama da branca & $\begin{array}{l}\text { Clavija lancifolia Desf. } \\
\text { Rhabdodendron amazonicum (Spruce } \\
\text { ex. Benth.) Huber }\end{array}$ & $\begin{array}{l}\text { Theophrastaceae } \\
\text { Rutaceae }\end{array}$ & & & * & \\
\hline Marapuama da vermelha & Non identifié & Non identifiée & & & * & \\
\hline Marapuama preta & Clavija lancifolia Desf. & Theophrastaceae & & & * & \\
\hline Marfim & Agonandra brasiliensis Miers & Opiliaceae & & & * & \\
\hline Marupá & Non identifié & Non identifiée & & & * & \\
\hline Mastruz & Non identifié & Poaceae & * & & & \\
\hline
\end{tabular}


Matapasto - Murteira branca

\begin{tabular}{|c|c|c|c|c|c|c|}
\hline Noms vernaculaires & Noms scientifiques & Familles & Jd & $A b$ & FdT & $\lg$ \\
\hline Matapasto & Non identifié & Poaceae & * & & & \\
\hline Maxixe & Cucumis anguria $L$. & Cucurbitaceae & & * & & \\
\hline Melancia & Citrullus lanatus (Thunb.) & Cucurbitaceae & & * & & \\
\hline Melhoral & Non identifié & Non identifiée & * & & & \\
\hline Mimorana & Non identifié & Non identifiée & & & * & \\
\hline Milho (2 variétés) & Zea mays L. & Poaceae & & * & & \\
\hline Mirindiba & Terminalia sp. (esp 2) & Combretaceae & & & * & \\
\hline Miri & Non identifié & Non identifiée & * & & & \\
\hline Mogno & Swietenia macrophylla King. & Meliaceae & * & * & * & \\
\hline Molongó & Non identifié & Apocynaceae & & & * & \\
\hline Morão branco & $\begin{array}{l}\text { Eschweilera sp. (esp 1) } \\
\text { Xylopia aromatica (Lam.) Mart. }\end{array}$ & $\begin{array}{l}\text { Lecythidaceae } \\
\text { Annonaceae }\end{array}$ & & & * & \\
\hline Morão cabeza de macaco & Non identifié & Lecythidaceae & & & * & \\
\hline Morão vermelho & $\begin{array}{l}\text { Eschweilera ovata Cambe } \\
\text { ss Xylopia sp. (esp 6) } \\
\text { Couratari sp. } \\
\text { Xylopia aromatica (Lam.) Mart. }\end{array}$ & $\begin{array}{l}\text { Lecythidaceae } \\
\text { Annonaceae } \\
\text { Lecythidaceae } \\
\text { Annonaceae }\end{array}$ & & & * & \\
\hline Mororó & Non identifié & $\begin{array}{l}\text { Fabaceae- } \\
\text { Caesalpinioideae }\end{array}$ & & & * & \\
\hline Morototó = Murucututu & $\begin{array}{l}\text { Schefflera morototóni (Aubl.) Decne \& } \\
\text { Planch. }\end{array}$ & Araliaceae & & & * & \\
\hline Mocaja & Acrocomia aculeata (Jacq.) Lodd. & Arecaceae & * & & * & \\
\hline Muiajuçara & Non identifié & Apocynaceae & & & * & \\
\hline Muirapixuna & $\begin{array}{l}\text { Zygia latifolia Fawc. \& Rendle } \\
\text { Casearia arborea H.B.K } \\
\text { Zygia sp. (esp 2) }\end{array}$ & $\begin{array}{l}\text { Fabaceae-Mimosoideae } \\
\text { Flacourtiaceae } \\
\text { Fabaceae-Mimosoideae }\end{array}$ & & & * & \\
\hline Mumbaca & Bactris mumbaca Mart. & Arecaceae & & & * & \\
\hline Munguba & Bombax muguba Mart. & Bombacaceae & & & * & \\
\hline Muruci comum & Byrsonima crassifolia H.B.K. & Malpighiaceae & * & * & & \\
\hline Murteira & $\begin{array}{l}\text { Myrcia fallax (Rich) D.C } \\
\text { Xylopia sp. (esp 4) }\end{array}$ & $\begin{array}{l}\text { Myrtaceae } \\
\text { Annonaceae }\end{array}$ & & & * & \\
\hline Murteira branca & Miconia sp. (esp 3) & Melastomataceae & & & * & \\
\hline
\end{tabular}

\section{Murteira vermelha - Pau careca}

\begin{tabular}{|c|c|c|c|c|c|c|}
\hline Noms vernaculaires & Noms scientifiques & Familles & Jd & $A b$ & FdT & Ig \\
\hline Murteira vermelha & $\begin{array}{l}\text { Licania sp. (esp 2) } \\
\text { Myrcia fallax (Rich) D.C }\end{array}$ & $\begin{array}{l}\text { Chrysobalanaceae } \\
\text { Myrtaceae }\end{array}$ & & & * & \\
\hline Muruci da beira da praia & Byrsonima sp. & Malpighiaceae & & & & * \\
\hline $\begin{array}{l}\text { Muruci da mata/Muruci } \\
\text { grande }\end{array}$ & Byrsonima sp. & Malpighiaceae & * & * & * & \\
\hline Mururé & Brosimum acutifolium Huber & Moraceae & & & * & \\
\hline Muúba & Bellucia sp. & Melastomataceae & & & * & \\
\hline Olho de cavalo ( $\neq$ do veado) & $\begin{array}{l}\text { Rhabdodendron amazonicum (Spruce } \\
\text { ex. Benth.) Huber }\end{array}$ & Theophrastaceae & & & * & \\
\hline Olho de veado & $\begin{array}{l}\text { Cupania sp. } \\
\text { Pouteria sp. (esp 6) } \\
\text { Rhabdodendron amazonicum (Spruce } \\
\text { ex. Benth.) Huber }\end{array}$ & $\begin{array}{l}\text { Sapindaceae } \\
\text { Sapotaceae } \\
\text { Theophrastaceae }\end{array}$ & & & * & \\
\hline Pajurá & Couepia bracteosa Benth. & Rosaceae & * & & & \\
\hline Papara da folha grande & Non identifié & Non identifiée & & & * & \\
\hline Papara da folha pequena & Non identifié & Non identifiée & & & * & \\
\hline Papaterra branca & Miconia sp. (esp 2) & Melastomataceae & & & * & \\
\hline Papaterra da preta & Miconia chrysophyllum & Melastomataceae & & & * & \\
\hline Papelinho & Zollernia paraensis Huber & $\begin{array}{l}\text { Fabaceae- } \\
\text { Caesalpinioideae }\end{array}$ & & & * & \\
\hline Paracutaca da mata & Helicostylis sp. & Moraceae & & & * & \\
\hline Paracutaca da praia & Helicostylis sp. & Moraceae & & & & * \\
\hline Parapara & $\begin{array}{l}\text { Jacarandá copaia (Aubl.) D.Don. } \\
\text { Simarouba amara Aubl. }\end{array}$ & $\begin{array}{l}\text { Bignoniaceae } \\
\text { Simaroubaceae }\end{array}$ & & & * & \\
\hline Pariri & Heliconia sp. & Heliconiaceae & & & * & \\
\hline Passarinheira & $\begin{array}{l}\text { Casearia arborea H.B.K } \\
\text { Lacistema pubescens Mart. }\end{array}$ & $\begin{array}{l}\text { Flacourtiaceae } \\
\text { Lacistemataceae }\end{array}$ & & & * & \\
\hline Passarinheira branca & Myrcia silvatica (G. Mey.) DC. & Myrtaceae & & & * & \\
\hline Passarinheira da vermelha & Lacistema pubescens Mart. & Lacistemataceae & & & * & \\
\hline Patauá & Oenocarpus bataua Mart. & Arecaceae & * & & & \\
\hline Pau amarelo & Non identifié & Non identifiée & & & * & \\
\hline Pau careca & Picramnia sp. & Simaroubaceae & & & * & \\
\hline
\end{tabular}


Pau d'arco amarelo - Pitanga da praia

\begin{tabular}{|c|c|c|c|c|c|c|}
\hline Noms vernaculaires & Noms scientifiques & Familles & Jd & Ab & FdT & Ig \\
\hline $\begin{array}{l}\text { Pau d'arco amarelo (=ipê } \\
\text { amarelo) }\end{array}$ & Tabebuia serratifolia (Vahl) Nichols & Bignoniaceae & * & * & * & \\
\hline Pau d'arco roxo (=ipê roxo) & Tabebuia incana Gentry & Bignoniaceae & & * & * & \\
\hline $\begin{array}{l}\text { Pau de canela da mata=Pau } \\
\text { de caneleira }\end{array}$ & $\begin{array}{l}\text { Eugenia sp. } \\
\text { Ormosia sp. }\end{array}$ & $\begin{array}{l}\text { Myrtaceae } \\
\text { Fabaceae }\end{array}$ & & & * & \\
\hline Pau da folha fina & Enterolobium maximum Ducke & Fabaceae-Mimosoideae & & & * & \\
\hline Pau de folha larga & Glycidendron amazonicum Ducke & Euphorbiaceae & & & * & \\
\hline Paù de macaco & Non identifié & Non identifiée & & & * & \\
\hline Pau de quina & Non identifié & Non identifiée & & & * & \\
\hline Pau de tocandeira & $\begin{array}{l}\text { Eschweleira sp.(esp 1) } \\
\text { Inga sp. (esp 7) } \\
\text { Poecilanthe effusa (Huber) Ducke }\end{array}$ & $\begin{array}{l}\text { Lecythidaceae } \\
\text { Fabaceae-Mimosoideae } \\
\text { Fabaceae- } \\
\text { Papilionoideae }\end{array}$ & & & * & \\
\hline Pau de tocandeira amarelo & Non identifié & Fabaceae & & & * & \\
\hline Pau de tocandeira vermelho & Thyrsodium paraense Huber & Anacardiaceae & & & * & \\
\hline Pau para tudo & Simaba cedron Planch & Simaroubaceae & & & * & \\
\hline Periquiteira da branca & Non identifié & Moraceae & & & * & \\
\hline Periquiteira da vermelha & Non identifié & Moraceae & & & * & \\
\hline Pernaubeira branca & Non identifié & Non identifiée & & & * & \\
\hline Pernaubeira preta & Non identifié & Non identifiée & & & * & \\
\hline Peroba & Passiflora sp. & Passifloraceae & * & & & \\
\hline Piasoqueira & Non identifié & Non identifiée & & & * & \\
\hline $\begin{array}{l}\text { Pimenta da mata } \\
\text { (=Pimenteira) }\end{array}$ & Non identifié & Solanaceae & & & * & \\
\hline Pimenta do reino & Piper nigrum $\mathrm{L}$. & Piperaceae & & * & & \\
\hline Pimenta malagueta comum & Capsicum sp. & Solanaceae & * & & & \\
\hline Pinauba $=$ Pinauba preta & Non identifié & Non identifiée & & & * & \\
\hline Piquiarana & Caryocar glabrum (Aubl.) Pers. & Caryocaraceae & & & * & \\
\hline Piquiá & Caryocar villosum (Aubl.) Pers. & Caryocaraceae & * & * & * & \\
\hline Pitanga da mata & Terminalia sp. (esp 1) & Combretaceae & & & * & \\
\hline Pitanga da praia & Non identifié & Myrtaceae & & & & * \\
\hline
\end{tabular}

Piririma branco - Seringueira do igapó

\begin{tabular}{|c|c|c|c|c|c|c|}
\hline Noms vernaculaires & Noms scientifiques & Familles & Jd & $A b$ & FdT & Ig \\
\hline Piriima branco & Bactris sp. (esp2) & Arecaceae & & & * & \\
\hline Piririma vermelho & Bactris sp. (esp2) & Arecaceae & & & * & \\
\hline Pitomba da casca vermelha & Talisia sp. (esp 1) & Sapindaceae & & & * & \\
\hline $\begin{array}{l}\text { Pitomba da mata da folha } \\
\text { larga/graúda =Pitomba da } \\
\text { alto=Pitomba grande }\end{array}$ & Talisia sp. (esp 2) & Sapindaceae & & & * & \\
\hline Pitomba da mata/amarelo & $\begin{array}{l}\text { Abuta grandifolia Mart. } \\
\text { Abuta sp. (esp 1) }\end{array}$ & Menispermaceae & & & * & \\
\hline Pitomba do quintal & Abuta sp. (esp 1) & Menispermaceae & * & & & \\
\hline Pitomba miúda/pequena & Abuta sp. (esp 1) & Menispermaceae & * & & * & \\
\hline Pororoqueira & Cynometra sp. & $\begin{array}{l}\text { Fabaceae- } \\
\text { Caesalpinioideae }\end{array}$ & & & * & \\
\hline Pupunheira & Bactris gasipae & Arecaceae & * & * & & \\
\hline Purui & Alibertia edulis A.Rich & Rubiaceae & & & * & \\
\hline Quiabo & Abelmoschus esculentus L. (Moench) & Malvaceae & & * & & \\
\hline Riz (arroz) & Oriza sativa L. & Poaceae & & * & & \\
\hline Roxinho & Non identifié & $\begin{array}{l}\text { Fabaceae- } \\
\text { Caesalpinioideae }\end{array}$ & & & * & \\
\hline Sacaca & Croton cajucara Benth. & Euphorbiaceae & & & * & \\
\hline Samambaia & Selaginella stellata Spring. & Selaginelaceae & & & * & \\
\hline Samaumeira & Non identifié & Non identifiée & & & * & \\
\hline Sapateira & Zanthoxylum sp. & Rutaceae & & & * & \\
\hline Sapupira (=Pau de pilão) & $\begin{array}{l}\text { Zygia racemosa } \\
\text { Vitex trifolia Vahl. }\end{array}$ & $\begin{array}{l}\text { Fabaceae-Mimosoideae } \\
\text { Verbenaceae }\end{array}$ & & & * & \\
\hline Sapupira do vermelho & Non identifié & Verbenaceae & & & * & \\
\hline Sapupira preta & Non identifié & Verbenaceae & & & * & \\
\hline Sarabatuco & Non identifié & Non identifiée & & & * & * \\
\hline Saritã & Picramnia sp. & Simaroubaceae & & & * & \\
\hline $\begin{array}{l}\text { Seringueira do amplo/ } \\
\text { seringueira do mato }\end{array}$ & Hevea brasiliensis Müll. Arg. & Euphorbiaceae & & & * & \\
\hline Seringueira do igapó & Hevea sp. & Euphorbiaceae & & & & * \\
\hline
\end{tabular}


Seringueira do oriente - Taxi liso

\begin{tabular}{|c|c|c|c|c|c|c|}
\hline Noms vernaculaires & Noms scientifiques & Familles & Jd & $A b$ & FdT & Ig \\
\hline $\begin{array}{l}\text { Seringueira do oriente/ } \\
\text { Seringueira americano }\end{array}$ & Hevea sp. & Euphorbiaceae & * & * & & \\
\hline Seringueira nativa & Hevea brasiliensis Müll. Arg. & Euphorbiaceae & * & * & * & \\
\hline Soroca da branca & Non identifié & Moraceae & & & * & \\
\hline Soroca vermelha & Non identifié & Moraceae & & & * & \\
\hline $\begin{array}{l}\text { Sucuúba branca } \\
\text { (= da casca branca) }\end{array}$ & $\begin{array}{l}\text { Himatanthus sucuuba Spruce ex Müll. } \\
\text { Arg. }\end{array}$ & Apocynaceae & * & * & * & \\
\hline Sucuúba preta & $\begin{array}{l}\text { Himatanthus sucuuba Spruce ex Müll. } \\
\text { Arg. }\end{array}$ & Apocynaceae & & & * & \\
\hline Sucuúba vermelha & Non identifié & Apocynaceae & & & * & \\
\hline Suveira & Pouteria sp. & Sapotaceae & & & * & \\
\hline Tabacarana/Maracana & Non identifié & Asteraceae & & & * & \\
\hline $\begin{array}{l}\text { Taboca da capoeira/ } \\
\text { Taboquinha }\end{array}$ & Non identifié & Polygonaceae & & & * & \\
\hline $\begin{array}{l}\text { Taboca da grande/grossa } \\
\text { Taboca da mata=Tabocão }\end{array}$ & $\begin{array}{l}\text { Coccoloba latifolia Lam. } \\
\text { Coccoloba sp. }\end{array}$ & Polygonaceae & & & * & \\
\hline Tamanqueira & Non identifié & Non identifiée & & & * & \\
\hline Tapereba & Spondias mombin $\mathrm{L}$. & Anacardiaceae & * & & * & \\
\hline Tapeúa & Non identifié & Non identifiée & & & * & \\
\hline Tapupira & Non identifié & Non identifiée & & & * & \\
\hline Taquari & Mabea angustifolia Spruce & Euphorbiaceae & & & * & \\
\hline Taquarirana & Swartzia sp. & $\begin{array}{l}\text { Fabaceae- } \\
\text { Papilionoideae }\end{array}$ & & & * & \\
\hline Tapiririca & Tapirira guianensis Aubl. & Anacardiaceae & & & * & \\
\hline Tauari & Couratari guianensis & Lecythidaceae & & & * & \\
\hline Taxi branco & $\begin{array}{l}\text { Sclerolobium sp. } \\
\text { Tachigali myrmecophila Ducke }\end{array}$ & $\begin{array}{l}\text { Fabaceae- } \\
\text { Caesalpinioideae }\end{array}$ & & & * & \\
\hline Taxi de vara & Non identifié & $\begin{array}{l}\text { Fabaceae- } \\
\text { Caesalpinioideae }\end{array}$ & & & * & \\
\hline Taxi fedorento & Tachigali myrmecophila Ducke & $\begin{array}{l}\text { Fabaceae- } \\
\text { Caesalpinioideae }\end{array}$ & & & * & \\
\hline Taxi liso & Non identifié & $\begin{array}{l}\text { Fabaceae- } \\
\text { Caesalpinioideae }\end{array}$ & & & * & \\
\hline
\end{tabular}

Taxi pedro - Urucu

\begin{tabular}{|c|c|c|c|c|c|c|}
\hline Noms vernaculaires & Noms scientifiques & Familles & Jd & $A b$ & FdT & lg \\
\hline Taxi pedro & Non identifié & $\begin{array}{l}\text { Fabaceae- } \\
\text { Caesalpinioideae }\end{array}$ & & & * & \\
\hline Taxi vermelho & $\begin{array}{l}\text { Tachigali myrmecophila Ducke } \\
\text { Sclerolobium sp. }\end{array}$ & $\begin{array}{l}\text { Fabaceae-Caesalpinioi } \\
\text { deae }\end{array}$ & & & * & \\
\hline Tenteiro amarelo & Swartzia sp. (esp 2) & $\begin{array}{l}\text { Fabaceae- } \\
\text { Papilionoideae }\end{array}$ & & & * & \\
\hline Tenteiro comum & Non identifié & $\begin{array}{l}\text { Fabaceae- } \\
\text { Papilionoideae }\end{array}$ & & & * & \\
\hline Tenteiro flamengo & Non identifié & $\begin{array}{l}\text { Fabaceae- } \\
\text { Papilionoideae }\end{array}$ & & & * & \\
\hline Tenteiro vermelho & Thyrsodium paraense Huber & Anacardiaceae & & & * & \\
\hline Tento verde/branco & Non identifié & $\begin{array}{l}\text { Fabaceae- } \\
\text { Papilionoideae }\end{array}$ & & & * & \\
\hline Terramicina & Non identifié & Non identifiée & * & & & \\
\hline Tiririca & Seleria sp. & Cyperaceae & & & * & \\
\hline Tucumã & Astrocaryum tucuma Mart. & Arecaceae & & & * & \\
\hline Tucumã açú & Astrocaryum tucuma Mart. & Arecaceae & & & * & \\
\hline Tucumã casado & Astrocaryum sp. & Arecaceae & & & * & \\
\hline Tucumã pitanga & Astrocaryum sp. & Arecaceae & & & * & * \\
\hline Tucumäi & Astrocaryum sp. & Arecaceae & & & * & * \\
\hline Ucuúba branca & Non identifié & Myristicaceae & & & * & \\
\hline Ucuúba vermelha & Non identifié & Myristicaceae & & & * & \\
\hline Unha de gato & $\begin{array}{l}\text { Bauhinia sp. } \\
\text { Zanthoxylum rhoifolium Lam. }\end{array}$ & $\begin{array}{l}\text { Fabaceae-Ca } \\
\text { esalpinioideae } \\
\text { Rutaceae }\end{array}$ & & & * & \\
\hline Urelheira grande & Enterolobium sp. & Fabaceae-Mimosoideae & & & * & \\
\hline Urelheira mióda & Enterolobium sp. & Fabaceae-Mimosoideae & & & * & \\
\hline Uruazeiro & $\begin{array}{l}\text { Cordia sp. (esp 1) } \\
\text { Cordia bicolor A.DC. }\end{array}$ & Boraginaceae & & & * & \\
\hline Uruazeiro branco & $\begin{array}{l}\text { Cordia sp. (esp 1) } \\
\text { Thyrsodium paraense Huber }\end{array}$ & $\begin{array}{l}\text { Boraginaceae } \\
\text { Anacardiaceae }\end{array}$ & & & * & \\
\hline Uruazeiro vermelho & Cordia sp. (esp 1) & Boraginaceae & & & * & \\
\hline Urucu & Bixa orellana $\mathrm{L}$. & Bixaceae & * & & & \\
\hline
\end{tabular}


Uxi do liso - Morphotype 2

\begin{tabular}{|c|c|c|c|c|c|c|}
\hline Noms vernaculaires & Noms scientifiques & Familles & Jd & $A b$ & FdT & $\lg$ \\
\hline Uxi do liso & Endopleura uchi (Huber) Cuatr. & Humiriaceae & & & * & \\
\hline Uxirana & Vatairea parviflora & Humiriaceae & & & * & * \\
\hline Vassoura & Non identifié & Myrtaceae & & & * & \\
\hline Vassoura da capoeira & Non identifié & Myrtaceae & & & * & \\
\hline Vassoura «alta» & Myrcia sp. (esp 2) & Myrtaceae & & & * & \\
\hline Vassoura branca & Myrcia silvatica (G. Mey.) DC. & Myrtaceae & & & * & \\
\hline Vassoura da mata & Non identifié & Myrtaceae & & & * & \\
\hline Vassoura folha grande & Myrcia silvatica (G. Mey.) DC. & Myrtaceae & & & * & \\
\hline Vassoura miúda/baixa & Myrcia silvatica (G. Mey.) DC. & Myrtaceae & & & * & \\
\hline Vassoura vermelho & Myrcia silvatica (G. Mey.) DC. & Myrtaceae & & & * & \\
\hline Vassourinha & Scopania dulcis (L.) Benth. & Serophulaniaceae & & & * & \\
\hline Verônica & Non identifié & Non identifiée & & & * & \\
\hline Umirizeiro & Humiria floribunda (Mart.) Cuatr. & Humiriaceae & * & & * & \\
\hline Morphotype 1 (sans nom) & Duquetia sp. (esp 2) & Annonaceae & & & * & \\
\hline Morphotype 2 (sans nom) & Quararibea sp. (esp 1) & Bombacaceae & & & * & \\
\hline
\end{tabular}

Légende : Jd : jardin, Ab : abattis, FdT : forêt de terre ferme, Ig : Igapó (forêt inondée).

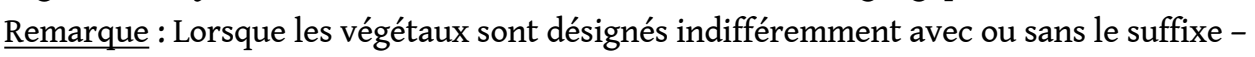
zeiro dans la nomenclature locale, ils sont indiqués ici sans le suffixe (ex : l'abiu est synonyme d'abiuzeiro, le breu de breuzeiro, etc.). De plus, toutes les lianes sont indiquées ici avec le préfixe cipó.

\section{NOTES}

1. Les morphotypes correspondent aux unités de reconnaissance des végétaux selon les villageois (Lawrence \& Mogea 1996) et correspondent au terme anglais folk-species (Phillips et al. 1994). Ce sont donc les « espèces locales ». Certains auteurs parlent également $d$ ' " ethnoespèces ».

2. Nous donnons ici la traduction littérale du nom en portugais, sans chercher à donner l'équivalent $\mathrm{du}$ nom populaire en vigueur en Guyane française où de nombreuses espèces se retrouvent.

3. Les exsudats sont nommés par différents termes locaux: "lait" (leite) lorsqu'il s'agit d'un exsudat assez liquide, blanc ou coloré (ex: cumaí, amapa, hévea, sucuúba, apuí), "huile" (óleo) lorsqu'il est plus liquide (copaiba), résine (breu) lorsqu'il est plus solide et relativement collant (jatobá, tenteiro vermelho). L'expression «sang de l'arbre» est aussi utilisée pour désigner les exsudats ou la sève.

4. Une série est un groupe de plantes ayant le même terme de base ; exemples la série du pin avec le pin sylvestre, le pin maritime, le pin d'Alep...

5. Feuilles opposées, alternes, lancéolées et acuminées pour les trois morphotypes.

6. Ces deux morphotypes n'ont pu être identifiés faute d'échantillons.

7. L'adjectif bravo signifie littéralement farouche ou courageux.

8. Un villageois interrogé a néanmoins clairement associé le stipe de la palmeira à un type de bois qui, selon lui, est utilisable dans l'artisanat local : "A palmeira, ela dá essa madeira que nem é o tucumã. Tem madeira por cima e dentro dele é ocado, ele tem uma massa fofa. A inajá é do mesmo jeito. Dá para usar a madeira para fazer artesanato."/ "Le palmier comme le tucumã produit du bois. Il y a du bois au dessus, et à l'intérieur c'est creux, il a une texture molle. L'inajá est pareil. On peut utiliser le bois pour faire de l'artisanat."[13]

9. Le commensalisme se différencie néanmoins du parasitisme au sens strict de par le caractère non destructeur de cette association pour l'hôte. 
10. Cette analyse de recoupement entre la taxonomie scientifique et la parataxonomie a été volontairement restreinte aux morphotypes de forêt de terre ferme car ceux-ci ont pu être identifiés par différents informateurs locaux lors des relevés ethnobotaniques menés dans des parcelles forestières.

11. Nous englobons ici deux cas de figure : 1) les morphotypes dont le nom de l'espèce botanique a été formellement identifié, 2) les morphotypes identifiés seulement au niveau générique mais qui ont été distingués les uns des autres au niveau spécifique (ex: Astrocaryum sp. (esp. 1), Astrocaryum sp. (esp. 2)...).

\section{RÉSUMÉS}

Cet article s'intéresse à la perception des végétaux d'une population traditionnelle vivant dans une aire protégée d'Amazonie brésilienne (les Ribeirinhos de la forêt nationale du Tapajós). Il traite successivement de l'identification et de la dénomination des plantes, des catégories locales des végétaux et de la correspondance entre nomenclature locale (parataxonomie) et nomenclature scientifique. Nous nous intéressons aux végétaux cultivés et spontanés, indépendamment du critère d'utilité des plantes pour la population locale. Seule l'analyse de la superposition de la taxonomie et parataxonomie s'est focalisée sur les espèces végétales forestières car celles-ci ont pu être identifiées par différents informateurs locaux lors d'inventaires ethnobotaniques dans des parcelles forestières.

Une approche en ethnobiologie et ethnobotanique quantitative a été développée afin d'analyser les savoirs écologiques locaux et de les mettre en parallèle avec les connaissances scientifiques. Une attention particulière a été apportée à l'analyse des discours des informateurs locaux.

Cette étude montre que la variation des critères pris en compte tant dans la reconnaissance que dans la dénomination des plantes (au niveau individuel et collectif) engendre une nomenclature locale riche et flexible, qui révèle une hétérogénéité des connaissances vis-à-vis de la diversité végétale. De plus, parallèlement à une opposition primordiale entre espèces domestiquées et espèces considérées sauvages, les Ribeirinhos distinguent neuf catégories englobantes de végétaux. Celles-ci se fondent sur des caractéristiques essentiellement morphologiques, avec cependant des superpositions possibles entre certaines catégories et des changements de catégories pouvant être opérés pour certains végétaux.

Au total, 439 morphotypes - ou ethnoespèces, unités minimales de perception de la biodiversité par la population locale - ont été recensés (arbres, palmiers, lianes, herbes), et 257 termes de base ont été relevés. Près de $77 \%$ de ces morphotypes (337) se rencontrent exclusivement en forêt de terre ferme. Parmi eux, 206 ont été identifiés (soit 61\%) et correspondent à 214 espèces botaniques distinctes. Les deux taxonomies (populaire et scientifique) ne se superposent que partiellement puisqu'à peine la moitié des morphotypes ont une correspondance unique et exclusive dans la taxonomie scientifique, et qu'un même morphotype peut renvoyer à plusieurs espèces de genres, voire de familles différentes.

This article deals with the perception that traditional people living in a protected area of the Brazilian Amazon (the Ribeirinhos of the Tapajós National Forest) have of the plants. It 
successively deals with the identification and naming of plants, the local categories of plants and the correspondence between local nomenclature (parataxonomy) and scientific nomenclature. We focused on spontaneous and cultivated plants, regardless of the criterion of utility for the local population, except however for the analysis of the overlay between taxonomy and parataxonomy which focused on forest plant species because they have been identified by various local informants during ethnobotanical inventories in forest plots.

We developed an approach in ethnobiology and quantitative ethnobotany to analyze local ecological knowledge and put it in parallel with scientific knowledge. Particular attention has been paid to the analysis of speeches from local informants.

This study shows that local nomenclature is rich and flexible. Such an heterogeneity of knowledge vis-à-vis plant diversity results from the variation of criteria used in the recognition and in naming the plants at individual and collective scales. Furthemore, in addition to a primary opposition between domesticated species and wild species, the Ribeirinhos distinguish nine categories of plants. The criteria used are mostly morphological but categories can overlap and fews species can change for other categories.

In total, 439 morphotypes - also called ethnospecies that means minimum units of perception of biodiversity by local population - have been identified considering trees, palms, vines, grasses and herbs, and 257 basic terms were found. Nearly 77\% of these morphotypes (337) occur exclusively in terrafirme forest. Among them, 206 were identified (61\%) and correspond to 214 different plant species. The two taxonomies (scientific and popular) overlap partially: half of the morphotypes match the scientific taxonomy (with unique and exclusive correspondence) and the same morphotypes may refer to several species (sometimes different genera or families).

\section{INDEX}

Mots-clés : ethnobotanique, classification populaire, correspondance parataxonomie-taxonomie scientifique, forêt nationale du Tapajós

Population Ribeirinhos

Index géographique : Amazonie, Brésil

Keywords : ethnobotany, folk classification, correspondence parataxonomy-scientific taxonomy, Ribeirinhos, Amazon, Tapajós National Forest, Brazil

\section{AUTEUR}

\section{CLAIRE COULY}

Post doctorante

UMR Espace-Dev, Centre IRD de Guyane

route de Montabo, BP 165, 97323 Cayenne Cedex, Guyane française

couly.claire@gmail.com 